\title{
Sprechqualität und psychische Beeinträchtigung nach der Therapie von Mundhöhlentumoren
}

\author{
Mund-, Kiefer- und Gesichtschirurgischen Klinik \\ der medizinischen Fakultät der \\ Friedrich-Alexander-Universität Erlangen-Nürnberg
}

\author{
Der Medizinischen Fakultät \\ der Friedrich-Alexander-Universität \\ Erlangen-Nürnberg
}

zur

Erlangung des Doktorgrades Dr. med. dent.

vorgelegt von

Natalja Böhm 


\section{Als Dissertation genehmigt von der \\ Medizinischen Fakultät der Friedrich-Alexander-Universität Erlangen-Nürnberg}

Vorsitzender des Promotionsorgans: Prof. Dr. Markus F. Neurath Gutachter: Prof. Dr. Dr. Florian Stelzle

Gutachter:

PD Dr. Anne Schützenberger

Tag der mündlichen Prüfung:

19.Oktober 2021 
Inhaltsverzeichnis

1. Summary

1.1 Background

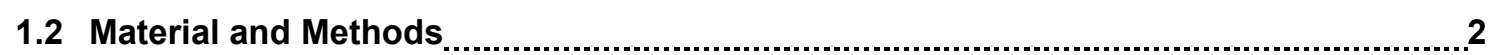

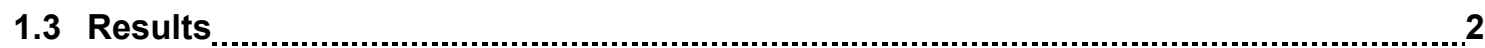

1.4 Conclusion

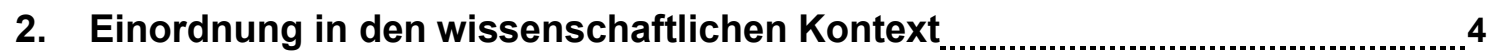

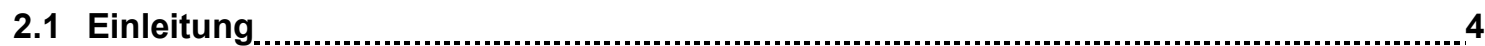

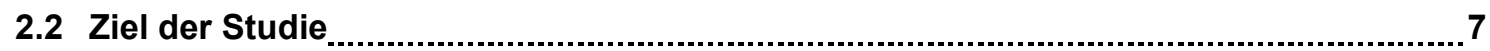

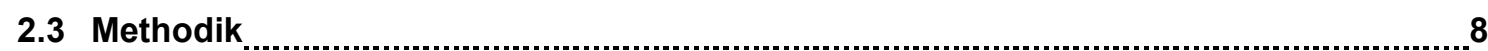

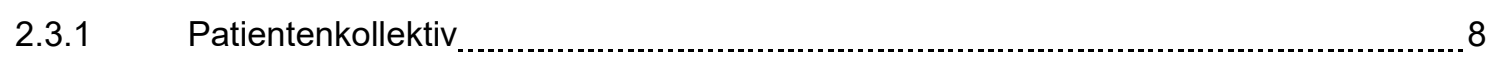

2.3.2 PEAKS: Program for Evaluation and Analysis of all Kinds of Speech disorders .........9

2.3.3 HADS: Hospital-Anxiety-and-Depression-Scale _................................................ 10

2.3.4 Gründe zur Untersuchung oder zum Ausschluss ausgewählter Parameter................11

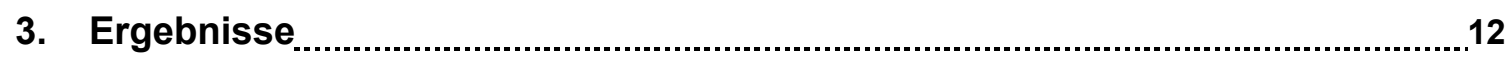

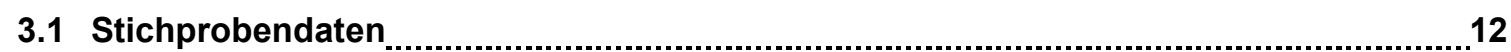

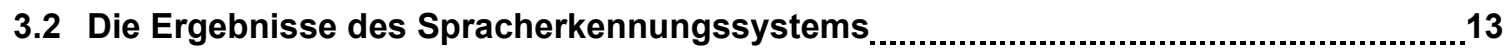

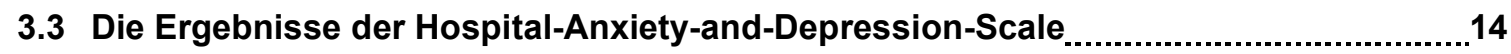

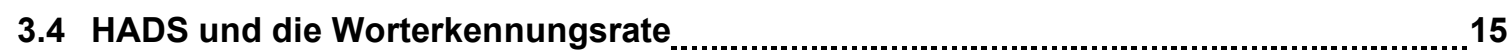

4. Diskussion und Ausblick

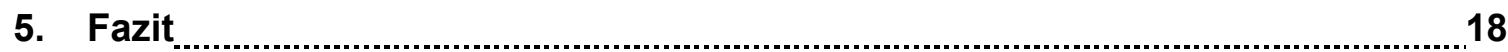

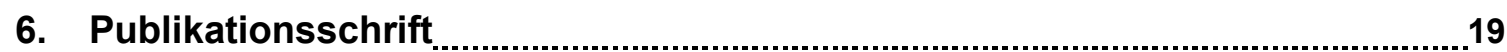

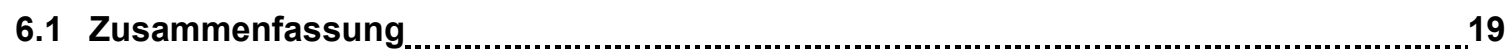

6.2 Summary 20

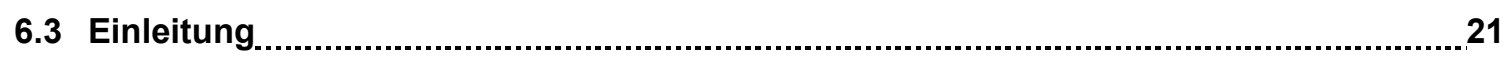

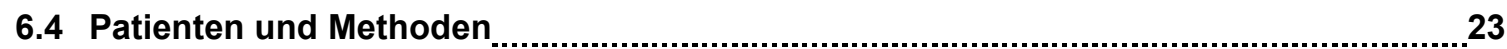

6.5 Testmaterial und Durchführung.

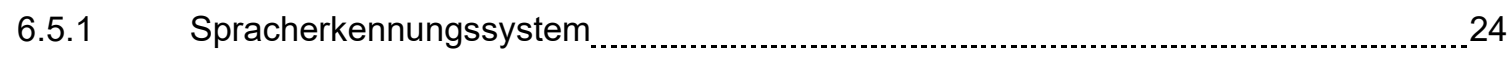

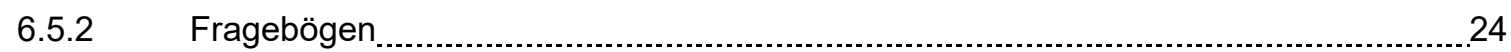

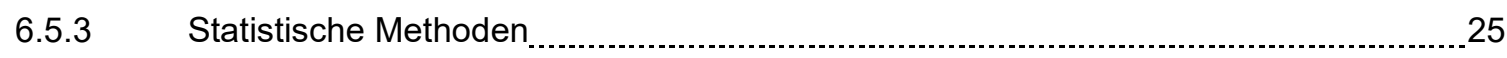

6.6 Ergebnisse

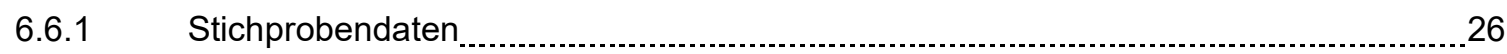

6.6.2 Sprachverständlichkeit und ihre Beziehungen zu anderen Parametern ......................28

6.6.2.1 WR-Mittelwerte und Ergebnisse des Spracherkennungssystems ....................28

6.6.2.2 Soziodemographische Parameter: Alter, Geschlecht und Nikotinabusus _........29

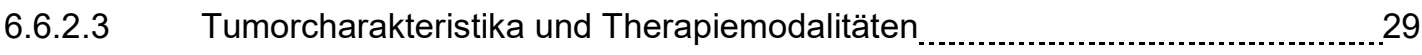

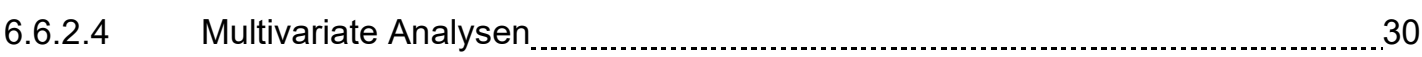


a) WR hinsichtlich Tumorgröße und Geschlecht _........................... 30

b) WR hinsichtlich Zungenbeweglichkeit und Tumorcharakteristika / Therapiemodalitäten

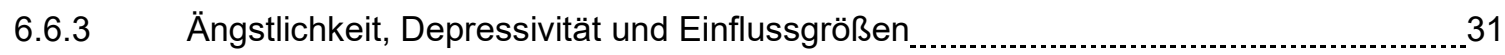

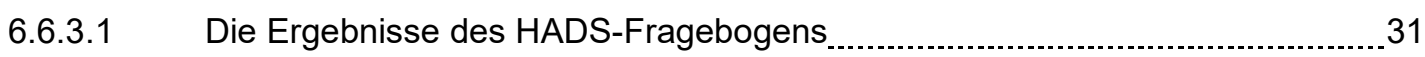

6.6.3.2 Soziodemographische Parameter: Alter, Geschlecht und Nikotinabusus ..........31

6.6.3.3 Tumorcharakteristika und Therapiemodalitäten .......................................... 31

6.6.4 Zusammenhang HADS - WR

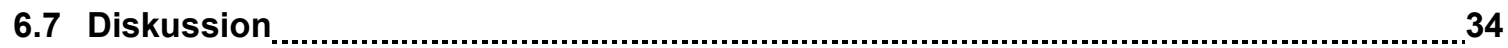

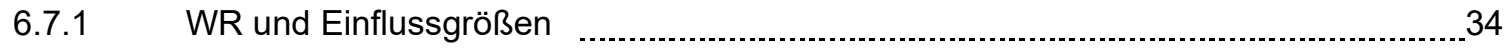

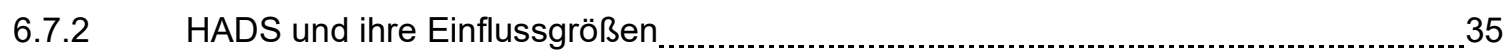

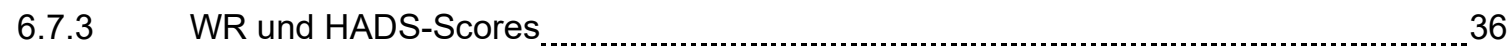

6.7.4 Beziehung zur Lebensqualität

6.7.5 Das psychologischen Befinden und das medizinische Outcome _ _ _ $\quad 37$

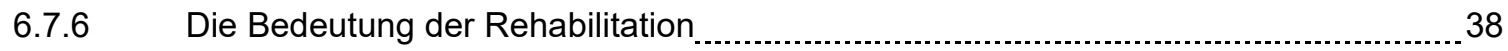

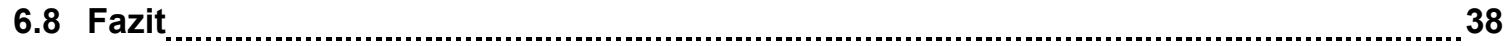

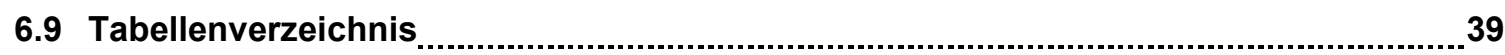

Tabelle 1: Stichprobenbeschreibung

Tabelle 2: Sprechverständlichkeit (WR) - Mittelwerte innerhalb der untersuchten Gruppen .........28

Tabelle 3: Sprechverständlichkeit (WR) und ihre Beziehungen zu anderen Parametern ..............33

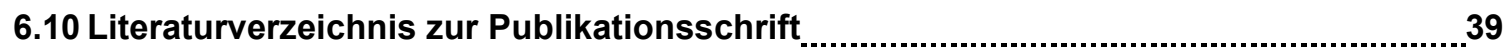

6.11 Lizenzgenehmigung zur Veröffentlichung der Publikationsschrift (Thieme-Verlag)....45

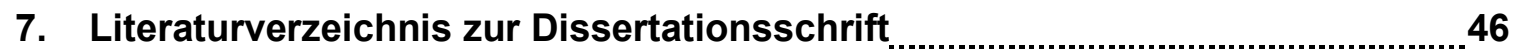

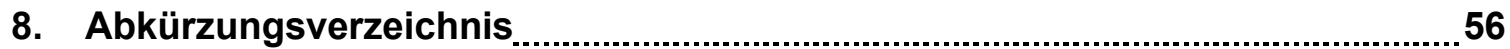

9. Danksagung (aus datenschutzrechtlichen Günden entfernt)

10. Lebenslauf (aus datenschutzrechtlichen Gründen entfernt) 


\section{Summary}

\subsection{Background}

Oral squamous cell carcinoma is with $95 \%$ the most common mouth malformation [1, 2 , 3]. With its highest incidence in men between 55 and 65 and women between 50 and 75 years of age, the lesions appear as mucosal white or red patches with slowly increasing growth. In higher stages they may be ulcerating or bleeding, causing discomfort, swelling, pain, functional restrictions like speech- or swallowing disability, halitosis and teeth mobility [1-5]. Mostly oral squamous cell carcinoma affects tongue, floor of the mouth, alveolar processes, cheeks, lips and palatial structures. Tonsils and pharynx may also be involved [1, 2, 5]. The 5-year-survival rate is actually on an average between $40-50 \%$. When the disease is not promptly diagnosed and treated immediately, it is associated with a very poor prognosis $[4,29]$. Proven reasons for this kind of cancer are: smoking, alcohol consumption and infections with HPV or EBV [423]. Other possible reasons are: lack of vitamins, local long-lasting irritations and bad oral hygiene [4, 11]. Latest trends like vaping devices, water pipes, other drugs and environmental toxicants with carcinogenic potential are gaining in importance and must be further evaluated [26-28].

The aim of the medical intervention for oral cancer is a curative treatment of the tumor including surgical removal of malignant tissue with its affected lymph nodes (neck dissection) and if necessary, combined with chemotherapy and radiotherapy [4, 34]. Defect reconstruction is often required during or after the surgical resection which may include local coverage techniques, free grafts or pedicle flaps $[4,34,35]$. In many cases, in spite of all efforts, the functional and aesthetic outcome is poor and causes residual disturbances such as dysphagia, insufficient oronasal separation, speech- and swallowing impairments, as well as loss of smell or sensitivity [34, 36-47]. In case of incurable stages, the palliative option with minimal invasive efforts should be preferred in order to reduce suffering during the survival time [4].

In recent years interactions between surgical treatment of oral carcinoma and incidence of anxiety or depression have become a subject of discussions. Many factors are described that may influence the functional and psychological outcome after surgery for oral squamous cell carcinoma. These are, for example, aspects like patient's age, his general condition, tumor staging, tumor localization, chosen therapy, degree of functional losses, tumor recurrence and rehabilitation measures $[4,14,34$, $41,43,47-50]$. Some aspects that affect patient's psychological outcome like negative pre-existing affective conditions, coping-strategies and difficulties with social interaction, financial problems and bad habits are closely related to his willingness and 
compliance to the therapy and modulate the therapeutic success $[32,33,37,38,51$ 63]. Communication skills and speech intelligibility are also presumed to interact with psychological outcomes, due to stress perception, limited social activities and feeling stigmatized as a result of disfigurement after surgery [32, 52]. More than thirty percent of patients report speaking problems following tissue remodeling [41, 42, 44, 65]. The aim of this study is a comparison between the extent of loss of speech intelligibility and presence of depressive symptoms or anxiety as a result of oral carcinoma.

\subsection{Material and Methods}

The required patient pool, in order to analyze possible factors that affect the intelligibility and psychological distress in patients after removal of oral carcinoma, originated in the Department of Oral- and Cranio-Maxillofacial Surgery University Hospital Erlangen with their encompassing diagnostic and therapeutic expertise.

One year after surgical therapy for oral carcinoma, 90 patients of an average age of $60 \pm 12$ years and free of tumor recurrence, were examined. In cooperation with the Department for Phoniatrics and Pedaudiology and Chair of Pattern Recognition, (University Erlangen-Nuremberg) an automatic speech recognition system (PEAKS) was used to analyze the speech quality of patients who previously underwent surgery. Their speech intelligibility degree was measured (word recognition rate, WR). Patient data about age, gender, tumor localization, tumor staging, graft donor site, graft morphology, tongue motility, radiotherapy and tracheotomy were recorded. Symptoms of anxiety and depression were detected by use of HAD-Scales (HADS). Beside the relationship between WR and HADS, other influential variables above related to WR and HADS, were statistically evaluated (IBM SPSS Statistics 22; SPSS Inc. an IBM Company, Chicago, IL).

\subsection{Results}

Speech ability: On an average, the WR was 53.2 \pm 17.2 . Female WR $(60.6 \pm 15.0)$ proved better than male $(51.3 \pm 18.2)$. The difference between tumor classifications T1 $(W R=60.3 \pm 15.6)$ and $T 4(W R=45.1 \pm 17.2)$ compared to the WR reached statistical significance $(p=0.009)$. Significant differences were detected between WR and "tumor localization" ( $p=0003)$ and for "graft donor site-", "graft morphology-“, "tongue motility-", and "tracheostoma-" groups. Graft donor site WR statistically worsened use of scapular or parascapular transplants combined with free bone grafts $(W R=44.1 \pm 18.1)$ compared to local plastic techniques ( $W R=60.0 \pm 16.9 ; p<0.001)$ and by use of radial forearm or lateral arm flaps $(W R=56.3 \pm 13.6)$ to scapular or parascapular transplants combined with free bone grafts $(p=0,003)$. Regarding graft morphology, the difference was shown 
in WR between local plastic techniques and fascio-myo-cutaneous flaps combined with free bone transplants $(W R=32.6 \pm 22 ; p=0,022)$ or rather osteo-myo-cutaneus flaps $(W R=48.1 \pm 16.4 ; p=0,006)$. WR was also significantly different for fascio-myo-cutaneus flaps $(\mathrm{WR}=54.6 \pm 15.3)$ in comparison with fascio-myo-cutaneous flaps combined with free bone transplants $(p=0.049)$. In the latter case, a small group size must also be taken into consideration.

A limited tongue motility defined a poor speech outcome $(p=0.007)$. There was a possible relationship between tongue motility and graft morphology (single factor variance $p<0.001$, but two factor variance tongue motility vs. graft morphology $p=0.167$ and graft morphology vs. WR $p=0.292$ ). Signs of a possible relationship between tongue motility and graft donor site were also indicated (single factor variance for motility vs. graft donor site $p=0.025$, but two factor variance for tongue motility vs. WR $\mathrm{p}=0.062$ ). The two factors, tongue motility and tumor localization combined together, significantly affected the WR $(p=0.010)$. Tracheotomy noticeably lowered the speech ability (WR=50.9 $\pm 17.9 ; p=0.040)$.

HADS: HADS-Scores in the mean were elevated: HADS-Total=43.3\% (10.87 \pm 6.4$)$, HADS-A $=43.3 \%(6.0 \pm 3.7)$ und HADS-D=51.1\% (4.9 \pm 3.5$)$. WR correlated with HADSD-Subscale $(R=-0.247, p=0.019)$, but not with HADS-A-Subscale. Socio-demographical factors such as "age," "gender" and "smoking" were not related to HAD-Scores. Analyzing descriptive statistics, HADS-Total, HADS-A and HADS-D for factor "tumor size" were slightly elevated. The other elevated scores were only related to HADS-D. These elevated scores could be indicated by the following groups: female gender, patients with T2-tumors, involvement of free flap grafts, tracheotomy and patients who gave up smoking after surgery.

\subsection{Conclusion}

Communication disorders, as a result of neoplasmic orofacial surgery, may still be related to extent of the treatment and to affective impairments one year following therapy. This should receive attention in the rehabilitation concept, including choice of reconstruction technique, postoperative functional rehabilitation, speech therapy and psycho-oncology care. Use of a validated speech analyzing system and psychological screening methods may be valuable additional resources. 


\section{Einordnung in den wissenschaftlichen Kontext}

\subsection{Einleitung}

Im Bereich der onkologischen Erkrankungen stellen Mundhöhlenkarzinome mit 95\% aller oralen Karzinome [1-3] die häufigste Form der Malignitäten dar. Diese sind meist intraoral erkennbar als zunächst flache, fleckige rote oder weißliche, Oberflächendefekte, später auch als sich ausbreitende, ulzerierende, manchmal auch blutende Epithelverdickungen mit zapfenförmigem Tiefenwachstum in späteren Stadien [4]. Betroffen sein können alle mit der Schleimhaut ausgekleideten Bereiche. Besonders oft zeigen sich die Pathologien an der Zunge, dem Mundboden, den Alveolarfortsätzen, den Lippen oder den Wangen, dem Gaumen. Auch die Tonsillen und die Pharynx können Veränderungen aufweisen [1, 2, 5]. Weitere vorliegende Befunde können vielfältig sein: Schmerzen, Schwellungen der betreffenden Bereiche, unter anderem auch der befallenen Lymphknoten, Motilitätseinschränkungen der Strukturen einhergehend mit Schluckstörungen, eingeschränkter Zungenbeweglichkeit oder funktionellen Sprechstörungen. Veränderte Zahnstellungen, Zahnlockerungen unklarer Genese, Foetor ex ore und Sensibilitätsstörungen können bei eingehender Diagnostik auffallen [1-5]. Die Erkrankung betrifft vor allem ältere Menschen: bei Männern liegt das beschriebene Erkrankungsalter zwischen 55 und 65, bei Frauen zwischen 50 und 75 Jahren [2, 5].

Nikotin- und Alkoholkonsum zählen dabei zu den größten Risikofaktoren zur Entstehung eines oralen Plattenepithelkarzinoms: das Rauchen sowie der Alkoholkonsum allein erhöht das Risiko der Erkrankung um das 6-fache, die Kombination der beiden Genussmittel erhöht das Erkrankungsrisiko jedoch gleich um das 30-fache [4, 6-10]. Das Vorliegen von Vitaminmangelerscheinungen, lokalen mechanischen Irritationen (zum Beispiel durch Prothesendruckstellen, scharfe Restaurationskanten) und schlechte Mundhygiene triggern die Entstehung der malignen Läsion aus deren Präkanzerosen [4, 11].

In den neueren Untersuchungen rückt der Fokus vermehrt auf Infektionserkrankungen wie HPV oder EBV. Der kausale Zusammenhang zwischen positiver HPV16-Serologie und der Entstehung von Oropharynxkarzinomen gilt als nachgewiesen und wurde bereits von der Internationalen Agentur für Krebsforschung (IARC) der Weltgesundheitsorganisation (WHO) in die Nomenklatur und von der Union internationale contre le cancer (UICC) in die TNM-Klassifikation maligner Tumoren eingebunden [4, 12-16]. Für die Erkrankung an einem HPV-16-assoziierten Karzinom wurde ein früheres Erkrankungsalter und eine signifikante Abhängigkeit von den Risikofaktoren Tabak- und Alkoholkonsum verdeutlicht [17, 18]. Das Vorliegen von 
dieser Tumorart ist im Vergleich mit nicht HPV-assoziierten Oropharynxkarzinomen mit besserer Überlebensprognose verbunden [19-22]. Basierend auf diesen Erkenntnissen wurde die bereits bestehende Empfehlung der Ständigen Impfkommission (STIKO) zur HPV-Immunisierung für Mädchen um die Impfung für Jungen erweitert [23].

Aktuell wird eine Wandlungstendenz in der Morbidität erhofft: es wird ein Rückgang der Erkrankungsfälle als Folge der Verfügbarkeit der HPV-Impfung erwartet [23]. Auch die Wirkung von Lifestylefaktoren wie Änderung in Konsummustern von Nikotin- und Alkohol, vor allem unter Frauen und Jugendlichen, können sich langfristig mit veränderten Erkrankungszahlen und Tumorformen in der Statistik niederschlagen [2426]. Die Bedeutung von weiteren potenziell karzinogenen aufgenommenen Substanzen, wie zum Beispiel in E-Zigaretten und Mischungen für Tabakerhitzer oder Wasserpfeifen enthalten, anderer Drogen oder auch Umweltgiften wird in den nächsten Jahren sicherlich ausführlich diskutiert werden müssen [26-28].

Die Mundhöhlenkarzinome gehen weiterhin mit einer schlechten Prognose einher: nach 5 Jahren beträgt die Überlebensrate 40-50\%, je nach Zeitpunkt der Diagnosestellung variierend $[4,29]$. Vor allem bedingt durch initial meist schmerzlose Tumorentwicklung bemerken die Patienten die Läsion oft verspätet, dabei ist eine möglichst schnelle Therapie der Neoplasie entscheidend für eine gutes TherapieOutcome. Weitere in der Literatur beschriebene Gründe für einen verzögerten Behandlungsbeginn sind unter anderem Fehlinterpretationen des Krankheitsbildes durch das untersuchende Personal, oder verspäteter Arztkontakt seitens des Erkrankten. Letzteres wird öfter bei Männern als bei Frauen verzeichnet und gründet auf geringerer Behandlungsbereitschaft in Verbindung mit psychologischen Verdrängungsmechanismen [4, 29-33]. Dies hat zur Folge, dass in vielen Fällen bereits zum Zeitpunkt der Diagnosestellung Befunde mit ungünstigerer TNM-Klassifikation vorliegen - gegebenenfalls mit höherem Grading, multifokal, nah- oder fernmetastasiert - und somit mit schlechten Prognosen verbunden sind [4].

Das Ziel der Malignomtherapie verfolgt einen möglichst kurativen Ansatz und bedeutet zumeist ablativ chirurgisches Verfahren mit Halslymphknotenausräumung und plastischer Deckung, das bei Bedarf durch Radio-, Chemo- oder Radiochemotherapie ergänzt wird [4, 34]. Als Maßnahmen zur Defektdeckung aus körpereigenem Gewebe kommen dabei primär Nahlappen- und Fernlappenplastiken zum Einsatz [4, 34, 35]. Im Fokus steht eine maximal effektive Resektion des Lokalbefundes unter Schonung der umgebenden Strukturen zum bestmöglichen Wiederherstellung von Funktion und Ästhetik. Jedoch bedeutet es zeitgleich auch das Involvieren von weiteren, gesunden morphologischen Strukturen als Transplantatentnahmestellen zulasten des zu versorgenden Bereiches und somit auch weitere möglichen postoperativen 
Funktionseinschränkungen neben den tumorbedingten Gewebsschäden. Den Patienten erwartet im Verlauf der Therapie eine Konfrontation mit Schmerzen und Funktionseinschränkungen wie Dysphagie, insuffiziente Trennung der Luftwege, Sprechstörungen, Verlust von Geruchssinn und Sensibilität in betroffenen Strukturen [34, 36-47]. Aus diesem Grund soll - das Alter, den Allgemeinzustand des Patienten und die Tumoroperabilität mitbetrachtet - in bestimmten Fällen dem palliativen Therapieweg Vorzug gegeben werden. Dies beschränkt in der Regel das operative Eingriffsausmaß, mindert die empfundene Therapiebelastung und erlaubt oftmals eine bessere Lebensqualität in der verbleibenden Überlebenszeit [4].

Viele für das funktionelle Outcome wichtige Parameter sind bereits durch Studien umfangreich beleuchtet worden. Dazu gehören "harte Faktoren“ wie das Alter, der Allgemeinzustand, die Tumorausdehnung (TNM-Klassifikation), Lokalisation, gewählte Therapie, das Ausmaß von Funktionseinbußen, das Rezidivverhalten und die Erfolge von Rehabilitationsmaßnahmen [4, 14, 34, 41, 43, 47-50]. Aber auch „weiche Faktoren“ wie der Umgang mit der Krankheit, das Vorliegen von psychologischen (Vor-) Erkrankungen oder negativen Bewältigungsstrategien, Probleme mit Interaktion im sozialen Umfeld, finanzielle Schwierigkeiten, ungünstige Gewohnheiten und vermutlich viele weitere beeinflussen die Genesungsprozesse von Betroffenen. Die genannten Aspekte sind wiederum eng miteinender verknüpft und an die Prozesse wie Selbstwahrnehmung bzw. Coping, Compliance und schlussendlich an die Art des Gesamt-Outcomes gekoppelt [32, 33, 37, 38, 51-63].

Somit stellt sich die Frage, welche der mit der Erkrankung verbundenen Größen direkt oder indirekt Einfluss auf den Genesungsprozess und die Rehabilitationserfolge nehmen. Während die genannten „harten“ Größen in der Literatur bereits mit starkem Konsens belegt sind, sind die Verknüpfungen zwischen den einzelnen „harten und weichen“ Größen oft nur ansatzweise untersucht. Die Genesungsprozesse werden multifaktoriell beeinflusst. Einige Verlaufsentwicklungen können in für die Therapeuten nicht greifbaren Bereichen stattfinden. Als sicher belegt gilt, dass die Patienten in den Zeiten während und einige Monate nach der Therapie akut an Einschränkungen der Lebensqualität, depressiven Verstimmungen, Problemen in der Interaktion im sozialen Umfeld leiden [32, 33, 36, 51-63]. Gerade hinsichtlich der Fähigkeit zur Kommunikation wird beschrieben, dass Einschränkungen des Sprechens im Alltag auch noch nach Jahren das Stressempfinden, die Aktivität und das Gefühl der Stigmatisierung und Resignation negativ beeinflussen [52, 64]. Mehr als zwei Drittel der Patienten sind zu gegebenen Zeitpunkten der Therapie von peripheren Lautbildungsstörungen infolge von morphologischen Veränderungen betroffen [41, 42, 44, 65]. Somit kann es von Bedeutung sein, die Ursachen für die therapiebezogene Sprechstörung und das 
entsprechende Ausmaß der Beeinträchtigung hinsichtlich der Zusammenhänge zu psychologischen Auffälligkeiten zu untersuchen.

\section{$\underline{2.2 \text { Ziel der Studie }}$}

Um die Interaktionen unter diesen Faktoren genauer zu analysieren, bietet sich hervorragend die Möglichkeit der Untersuchung und Datenerhebung von Patienten der Tumor- und Tumornachsorgesprechstunde an. Die Mund-Kiefer-Gesichtschirurgische Abteilung der Universitätsklinik der Friedrich-Alexander-Universität Erlangen-Nürnberg bietet dazu einen umfassenden diagnostischen und therapeutischen Erfahrungsschatz und ermöglicht eine retrospektive Betrachtung der Ergebnisse im Rahmen der postoperativen Nachsorge.

In Kooperationsrahmen mit der Phoniatrie der HNO-Klinik und dem Lehrstuhl für Mustererkennung besteht hier seit 2006 die Möglichkeit, den Entwicklungsverlauf über den Zeitraum des Erstkontaktes in der onkologischen Sprechstunde bis über postoperativen Kontrollen und den Tumornachsorgesprechstunden über Jahre hinaus interdisziplinär zu verfolgen. Unter anderem lassen sich dabei Veränderungen im Bereich des Lautbildungssystems objektiv mittels eines automatisierten Spracherkennungssystems erfassen. Diese Daten bilden eine wichtige Grundlage für die Analyse zu dem Grad der kommunikativen Funktionsbeeinträchtigung vor und nach der Therapie und lassen sich gut mit den krankheitsrelevanten „harten Faktoren“ abgleichen. Das Projekt wurde in mehrere Studien für verschiedene Arbeitsgruppen aufgegliedert; daraus entstanden in den Jahren 2006 bis 2012 Untersuchungen zu dem Thema periphere Lautbildungsstörungen und deren Zusammenhang zu Normkollektiven [46, 66], Patientenkollektiven wie zum Beispiel Kindern mit LippenKiefer-Gaumenfehlbildung [67, 68], Prothesenträgern [69,70], Laryngektomierten Patienten [71] und Patienten mit Tumoren der Mundhöhle [37, 40, 43, 46, 47, 66]. Im Rahmen der entstandenen Veröffentlichungen zu Tumorpatienten sind die "harten“ Faktoren wie Tumorgrößen, Lokalisationen, Therapiearten, Geschlechter- und Altersverteilungen untersucht worden [37, 40, 43, 46, 47, 72]. Aber auch eine Studie zu psychologischen Aspekten, speziell zu Bewältigungsstrategien, fand statt [37]. Die meisten dieser Arbeiten haben jedoch einen retrospektiven Charakter, da die Sprechverständlichkeit in vielen Fällen zunächst erst postoperativ im Rahmen der Tumornachsorgesprechstunde erhoben und mit gesunden Normkollektiven verglichen werden konnte. Nach einer erfolgreichen Anlaufzeit des Projektes konnte die Verständlichkeit auch präoperativ erhoben werden, um somit Vergleiche zwischen präund postoperativen Werten zu ermöglichen [66], wodurch die Ergebnisse theoretisch auch Überprüfungen der Werte auf prognostische Inhalte zulassen. Zusammenfassend 
liefern die Ergebnisse der Arbeitsgruppen eine fundierte Datenmenge, die die Betrachtung einzelner Einflussgrößen auf dem Weg zu jeweiligen klinischen Outcomes ermöglicht.

Die nachfolgende Arbeit ist eine weitere Teilstudie des umschriebenen Projektes. Die Datenerhebung basiert auf der gleichen apparativen Ausstattung und wird im Folgenden beschrieben. Die Ergebnisse der vorliegenden Arbeit wurden in Form einer Vorabpublikation veröffentlicht in: Laryngo-Rhino-Otologie 2016 (Georg Thieme Verlag KG Stuttgart / New York); „Sprechqualität und psychische Beeinträchtigung nach der Therapie von Mundhöhlentumoren / Speech Ability and Psychological Outcome After Treatment of Oral Cancer“. N. Böhm, C. Knipfer, A. Maier, T. Bocklet, M. Rohde, F. W. Neukam, F. Stelzle, M. Schuster. Laryngo-Rhino-Otol 2016; 95(09): 610-619; DOI: 10.1055/s-0042-102256.

Das Ziel der Studie war der Abgleich der krankheits- und therapiebezogenen Daten auf potenzielle Zusammenhänge hinsichtlich psychologischer Beeinträchtigungen Ängstlichkeit und Depressivität in der Intention, das Ausmaß der Sprechstörung bestimmten operationsbedingten Faktoren zuordnen zu können und mögliche Zusammenhänge zwischen Erkrankungsparametern und psychologischer Verfassung der Patienten herauszufinden. Die Untersuchungen zur Sprechqualität sollen die diskutierten Größen wie Alter, Geschlecht, Tumorlokalisation, Tumorgröße und Rekonstruktionsart um Parameter Rauchverhalten und Bewegungseinschränkungen der Zunge mittels multivariater Analysen vervollständigen und erweitern. Zeitgleich sollten diese, hauptsächlich durch Erkrankung und Therapie bedingten Größen auf Zusammenhänge zur psychischen Befindlichkeit der Patienten geprüft werden.

\subsection{Methodik}

\subsubsection{Patientenkollektiv}

Folgende Voraussetzungen für die Studiendurchführung waren an der Abteilung für Mund-Kiefer-Gesichtschirurgie der Universitätsklinik Erlangen-Nürnberg gegeben und wurden für die Studie genutzt:

1. die Verfügbarkeit eines passenden, zu statistischer Auswertung ausreichend großen Kollektivs mit gesicherter Datenlage prä- und postoperativ;

2. das Bestehen eines etablierten Recallsystems mit der Möglichkeit zur Untersuchung vor Ort (hier inhaltlich wichtig als Verlaufskontrolle, Sicherung der Rezidivfreiheit, Überprüfung der Zungenbeweglichkeit);

3. das Vorhandensein einer automatisierten, zuverlässigen, benutzerunabhängigen Spracherkennungstechnik (Gewährleistung der Datenqualität); 
4. die Möglichkeit zur Durchführung einer Befragung zu dem Krankheitserleben, in diesem Fall für Ängstlichkeit und Depression.

Das auf diesen vier Säulen aufgebaute Konzept beinhaltete folgendes Vorgehen: die Patienten, die nach der chirurgischen Entfernung eines Plattenepithelkarzinoms sich in der Tumornachsorgesprechstunde vorstellten, wurden im Anschluss an die Sprechstunde direkt vor Ort über das laufende Projekt informiert. Wenn eine Bereitschaft zur Teilnahme bestand, wurden Sie von dem durchführenden Personal in den Untersuchungsraum eingeladen und über den Verlauf aufgeklärt. Die Einwilligung zur Teilnahme konnte jederzeit revidiert werden, diese Möglichkeit ist jedoch erfreulicherweise von keinem der Untersuchten in Anspruch genommen worden. In den Jahren 2008 bis 2010 konnten dabei 90 Patienten im durchschnittlichem Alter von $60 \pm 12$ für diese Teilstudie selektiert werden, die folgende Anforderungen erfüllten: histologisch gesicherte Befunde mit Plattenepithelkarzinomen der Mundhöhe, primär chirurgische Versorgung mit Zustand von 12 bis 16 Monaten postoperativ, Rezidivfreiheit zum gewählten Untersuchungszeitpunkt. Die Daten zu den Befunden und Therapiemaßnahmen wurden per Aktenlage erfasst, diese beinhalteten: das Alter, das Geschlecht, die Tumorgröße und Lokalisation, das Rauchverhalten, die Art der Defektdeckung, die Durchführung einer Strahlentherapie, das Vorhandensein eines Tracheostoma. Durch einen erfahrenen Arzt wurde vor der Anfertigung der Sprachaufnahme die Zungenbeweglichkeit visuell erfasst.

\subsubsection{PEAKS: Program for Evaluation and Analysis of all Kinds of Speech disorders}

Nach abgeschlossener Untersuchung erfolgte die Messung des Verständlichkeitsgrades mittels digitalisierter Sprachaufnahmen. Dafür wurden die Patienten nach einer kurzen Erklärung der Funktionsweise des Tests gebeten, möglichst deutlich einen vordefinierten Text vorzulesen. Dieser wurde mittels eines Spracherkennungsprogramms (PEAKS) aufgezeichnet und automatisiert ausgewertet. Das automatisierte Bewertungssystem der Sprechverständlichkeit, das zur Anwendung kam, ist eine Entwicklung am Lehrstuhl für Mustererkennung der Universität ErlangenNürnberg. Das einfach zu bedienende Programm berechnet standardisiert und vollautomatisiert den Verständlichkeitsgrad (Bezeichnet als "Worterkennungsrate“, „WR“) aus einer vordefinierten, gesprochenen Wortkette, indem es diese synchron zur Aufnahme auf akustische Übereinstimmung zu Modellwörtern überprüft. Als Referenzwerte verwendet das Programm die Sprachaufnahmen von über 600 gesunden Sprechern und kann nach dem Hidden-Markov-Modell die 
Worterkennungsrate berechnen, die den Prozentsatz aller als korrekt erkannter Worte abbildet [45, 73]. Die Übereinstimmung mit der subjektiven Bewertung der Sprachtherapeuten liegt laut Literaturlage sehr hoch $(r=-0,92)[45,46]$. PEAKS ist mittlerweile als online-client verfügbar und ermöglicht so auch die Verwendung für weitere klinische und analytische Zwecke für autorisiertes Personal. Die Verarbeitung der personenbezogenen Daten erfolgt pseudonymisiert. Die Ergebnisse werden in Echtzeit berechnet und stehen schon kurz nach der Aufnahme zum Download bereit. Dadurch ist es möglich, schnell, effizient, untersucherunabhängig und kostengünstig zuverlässige Ergebnisse zur Sprechqualität jedes Probanden zu erhalten. Durch das Vorhandensein einer objektiven, untersucherunabhängigen und einfach einzusetzenden Messmethode besteht hier die Möglichkeit zum Screening eines beliebigen Kollektivs in einer zuverlässigen, schnellen und reproduzierbarer Art und Weise. In die vorliegende Studie wurden jedoch nur Patienten mit deutscher Muttersprache aufgenommen, um eventuelle kulturell bedingten Abweichungen in der Phonetik beziehungsweise Sprechqualität auszuschließen.

\subsubsection{HADS: Hospital-Anxiety-and-Depression-Scale}

Der HADS-Fragebogen ist ein Selbstbeurteilungsfragebogen und wurde bereits 1983 von Zigmond und Snaith entwickelt [74]. Überarbeitet von Hermann et al. und übersetzt in deutsche Sprache ist dieser zu einem soliden Instrument zum Screening auf Angstund Depressionsmerkmale in der somatischen Medizin geworden [75]. Der Fragebogen ist gut validiert, verfügbar in mehreren Sprachen und findet nicht zuletzt wegen seiner schnellen und einfachen Anwendungen einen weltweiten Einsatz [74-78]. Zum weiteren Vorteil des Bogens gehört die Gestaltung der Fragen zur psychischen Befindlichkeit: diese sind bewusst von dem somatischen Erleben entkoppelt. Dadurch, dass die Items die Vermischung der beiden Ebenen vermeiden, empfindet ein Patient mit primär somatoformen Leiden sich nicht als psychiatrischer Patient vorverurteilt, sondern nur zu seiner Befindlichkeit befragt. Dies erleichtert die Akzeptanz zum Screening und dient als Einstieg in die Thematik hinsichtlich der tatsächlichen psychologischen Beeinträchtigung [75]. Auch auf dem Gebiet der Kopf-Hals-Tumoren haben sich die Skalen als hilfreich erwiesen [59, 78].

Nach der Anfertigung der Sprachaufnahme hatten die Testpersonen Zeit, möglichst ungestört den Fragebogen zur Evaluation von ängstlichen und depressiven Symptomen (HADS) auszufüllen. Waren die Patienten aufgrund ihrer körperlichen Verfassung (zum Beispiel durch Bewegungseinschränkungen jeglicher Art, nachlassende Sehkraft) nicht imstande, den Bogen ohne Fremdhilfe auszufüllen, wurde innen von dem untersuchenden Personal dabei geholfen. Hier galt es darauf zu 
achten, den Patienten in seinen Antworten keineswegs zu beeinflussen: gerade bei Anwesenheit von Angehörigen schienen einige unsicherer als allein. Das Genieren für die eigene Verfassung und eigene Gefühle schien für die wahrheitsgemäße Beantwortung der Fragen eine Rolle zu spielen. Ebenso führte ein hektisches oder dominierendes Auftreten der Begleitpersonen gelegentlich zu dem Umstand, dass die Antworten auf gestellte Fragen eher vom Begleiter suggeriert und vom Betroffenen einfach bejaht wurden. Um in solchen Fällen Reevaluationen zu vermeiden, hatte man auf die Anwesenheit der Begleitpersonen bei der Befragung möglichst verzichtet.

Anschließend wurden die erhobenen Daten in SPSS eingepflegt und statistisch ausgewertet (IBM SPSS Statistics 22; SPSS Inc. an IBM Company, Chicago, IL). Die Schwerpunkte der Auswertung bildeten der Vergleich der einzelnen soziodemographischen und morphologischen Faktoren mit den Werten der Sprechqualität sowie HADS-Ergebnissen und die Präzisierung möglicher Interaktionen durch die multivariaten Analysen untereinander.

\subsubsection{Gründe zur Untersuchung oder zum Ausschluss ausgewählter Parameter}

Als Daten für soziodemographische Faktoren wurden ausschließlich therapierelevante Merkmale aufgezeichnet. Es wurde bewusst auf Informationserfassung zu familiärer Situation, ökonomischen Verhältnissen, Beruf und ähnlichen verzichtet, um den Fokus der Patienten auf somatisch-funktionelle Aspekte der Untersuchung zu legen. Auf diese Weise sollte die geforderte Entkopplung von somatischen und psychischen Aspekten, wie für die Erhebung mittels HAD-Skalen gewünscht, unterstrichen werden. Ebenso wurden die Daten zu Sprechverständlichkeit präoperativ, Rehabilitations- und Logopädiemaßnahmen postoperativ aus der Analyse ausgelassen. Mit der Sprachverständlichkeit präoperativ beschäftigten sich in diesem Zeitraum gezielt Arbeitsgruppen des Projektes, die im Ergebnis bei einem erkrankten Kollektiv eine verminderte Worterkennungsrate im Vergleich zu gesundem Normkollektiv nachweisen konnten [43, 66]. Die Rehabilitations- und Logopädietherapie postoperativ waren konzeptionell zu einem großen Teil in Anpassung an individuelle und logistische Erfordernisse der Patienten angepasst und verliefen somit oft außer Haus. Die vorhandene Datenlage dazu war dadurch zum Zeitpunkt der Erhebung nicht vollständig und statistisch nicht aussagekräftig genug dokumentiert.

Zu den Parametern, die 12 bis 16 Monate postoperativ vollständig und statistisch im ausreichenden Maße erfasst werden konnten, gehören: Alter, Geschlecht, Nikotinabusus, Tumorgröße, Tumorlokalisation, Transplantatentnahmestelle, Transplantatmorphologie, Zungenbeweglichkeit, Strahlentherapie, Tracheostomie. Diese konstanten Größen wurden zum Kern der Untersuchung, da sie im 
Zusammenhang mit dem funktionellen Outcome stehen und zahlreich diskutiert wurden [34, 47, 79]. Aus diesen Kenngrößen ließen sich mit Hilfe des automatisierten Spracherkennungssystems PEAKS potenzielle Einflüsse auf die Sprechqualität herleiten, die statistische Signifikanz erreichten.

Die Studie wurde durch die Ethikkommission der Universität Erlangen-Nürnberg genehmigt (Antragsnummer 3732), gefördert durch die Wilhelm-Sander-Stiftung (20072009) und fand unter Beachtung der Helsinki-Deklaration 1975 (1983) statt.

\section{Ergebnisse}

\subsection{Stichprobendaten}

Von insgesamt 97 untersuchten Personen (davon 76 männlich und 21 weiblich) konnten nach Überprüfung der Einschlusskriterien 90 Patienten (70 männlich $(77,7 \%)$ und $20(22,2 \%)$ weiblich) in die Studie aufgenommen werden. Von den von der Studie ausgeschlossenen Patienten sprachen 4 nicht ausreichend dialektfrei, sodass PEAKSErgebnisse verfälscht schlecht ausfielen. Bei 3 Patienten kam es innerhalb von kurzer Zeit nach der Erhebung zu einem Rezidiv. Der allgemeine Altersdurchschnitt der verbliebenen 90 Patienten lag bei $60 \pm 12$ Jahren (68 \pm 15 für Männer und $58 \pm 10$ für Frauen). Anamnestisch lagen Tumorgrößen T1 bis T4 mit ähnlicher Verteilung innerhalb der Geschlechter vor: T1 (43,3\%), T2 (17,8\%), T3 (10,0\%) und T4 $(28,9 \%)$ (Verteilungen innerhalb der Geschlechter in Abb.1). Es lagen Befunde mit Plattenepithelkarzinomen des Mundbodens (41,1\%), der Zunge (31,1\%), des Oberkiefers $(7,8 \%)$ und des Unterkiefers $(20,0 \%)$ vor (Verteilungen innerhalb der Geschlechter in Abb.2).

Abb. 1: Verteilung der Tumorgrößen innerhalb der Geschlechter in \%

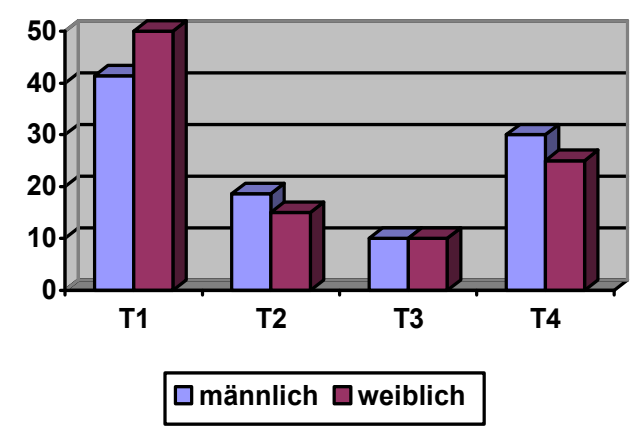

Abb. 2: Verteilung der Tumorlokalisationen innerhalb der Geschlechter in \%

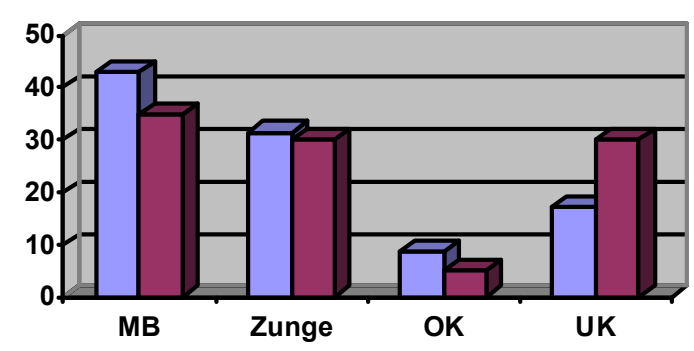

口männlich $\square$ weiblich 
Bei $71,1 \%$ lag ein Zustand nach Radiatio und bei $67,8 \%$ nach Tracheostoma vor. Die Defektdeckung erfolgte entweder lokalplastisch (25,6\%) oder mittels mikrovaskulär gestielter Transplantate wie Oberarm- / Unterarmtransplantate $(41,1 \%)$, Scapula-/ Parascapulatransplantate bzw. Fibulatransplantate (33,3\%). Diese wurden in Gruppen eingeteilt, die die Morphologie der Transplantate wiedergeben: faszio-/myo-/kutan $(42,2 \%)$, faszio-/myo-/kutan in Verbindung mit freiem Knochentransplantat $(4,4 \%)$ oder osteomyokutan (27,8\%). Die postoperative Zungenbeweglichkeit, die in 3 Schweregrade eingeteilt wurde, ergab folgende Werte: $47,8 \%$ für die Gruppe I (Patienten ohne bzw. mit nur geringfügiger Einschränkung in vertikaler und bzw. oder horizontaler Richtung); 33,3\% für die Gruppe II (Patienten mit mittlerer Bewegungseinschränkung) und $18,9 \%$ für die Gruppe III (Patienten mit starker Bewegungseinschränkung).

Die ausführlichen Tabellen, angewandten Testverfahren und Werte zu absoluten und relativen Verteilungen zu den genannten Parametern innerhalb der Geschlechter können aus der im Folgenden angefügten Publikation entnommen werden.

\subsection{Die Ergebnisse des Spracherkennungssystems}

Die ermittelten Werte zur Sprachverständlichkeit lagen bei einem WR-Mittelwert von $53,2 \pm 17,2$. Ein signifikanter Zusammenhang zwischen dem Alter und der WR konnte nicht nachgewiesen werden. Für Frauen $(W R=60,6 \pm 15,0)$ konnte eine signifikant höhere Worterkennungsrate nachgewiesen werden $(p=0,029)$ als für männlichen Patienten (WR=51,3 $\pm 18,2)$. Für die Tumorgrößen ließ sich nur zwischen T1 $(W R=60,3 \pm 15,6)$ und T4 $(W R=45,1 \pm 17,2)$ ein Unterschied in der WR feststellen $(p=0,009)$. Die Verständlichkeit bei Tumoren im Mundboden (WR=51,5 $\pm 13,6)$ war am höchsten, gefolgt von Lokalisationen in der Zunge (WR=50,0 $\pm 12,9)$, in dem Unterkiefer $(W R=49,0 \pm 13,1)$ und dem Oberkiefer $(W R=34,9 \pm 15,3)$; die Ergebnisse waren auf Signifikanzniveau unterschiedlich $(p=0,003)$.

Bei dem Vergleich zwischen lokalplastischer Deckung (WR=60,0 $\pm 16,9)$ zu mikrovaskulär reanastomosierten Transplantaten ließ sich kein signifikanter Unterschied für die Verwendung von Ober-/Unterarmtransplantaten feststellen (WR= $56,3 \pm 13,6 ; p=0,159)$. Jedoch verschlechterte sich die Wortverständlichkeit im Vergleich zwischen lokalplastischer Deckung zu Scapula-/Parascapula- bzw. Fibulatransplantaten (WR=44,1 $\pm 18,1 ; p<0,001)$ und von Ober-/Unterarmtransplantaten zu Scapula-/Parascapula- bzw. Fibulatransplantaten $(p=0,003)$.

Bei der Betrachtung von Transplantatmorphologien wurden diese paarweise untereinander verglichen. Hier ergab eine Deckung mit faszio-/myo-/kutanen 
Transplantaten in Verbindung mit einem freien Knochentransplantat (WR=32,6 $\pm 22,4)$ schlechtere WR-Ergebnisse als eine lokalplastische Deckung $(p=0,022)$. Ebenso fiel die Wortverständlichkeit bei osteomyokutanen Transplantaten $(\mathrm{WR}=48,1 \pm 16,4)$ schlechter aus als bei einer lokalplastischer Deckung $(p=0,006)$. Der Unterschied in der WR zwischen mikrovaskulär reanastomosierten faszio-/myo-/kutanen Transplantaten (WR von 54,6 $\pm 15,3$ ) und faszio-/myo-/kutanen Transplantaten in Verbindung mit einem freien Knochentransplantaten fiel unter Berücksichtigung der kleinen Fallzahl auch signifikant aus $(p=0,049)$.

Bei der Zungenbeweglichkeit unterschieden sich die WR-Werte der einzelnen Gruppen global voneinander $(p<0,001)$. Die Gruppe mit der Stufe I $(W R=60,9 \pm 14,0)$ erzielte im Vergleich zur Gruppenstufe II $(51,4 \pm 15,4 ; p=0,030)$ und zur Gruppenstufe III $(W R=36,7 \pm 15,8 ; p=0,001)$ bessere Ergebnisse, sowie die Ergebnisse der Gruppe mit der Stufe III im Vergleich zur Gruppenstufe II schlechter ausfielen $(p=0,007)$. Dabei bestand ein Zusammenhang zwischen der Transplantatmorphologie und der Zungenbeweglichkeit $(p<0,001)$, wobei dieser Effekt im zweifaktoriellen Vergleich hinsichtlich WR an Signifikanz verlor (Vergleich von Zungenbeweglichkeit mit Transplantatmorphologie bei $p=0,167$, Vergleich von Transplantatmorphologie mit WR bei $p=0,292$ ). Das gleiche gilt auch für den Zusammenhang zwischen den Faktoren „Zungenbeweglichkeit" und „Transplantatentnahmeregion“: bei vorhandener Signifikanz im einfaktoriellen Vergleich $(p=0,025)$ reduzierte sich der nachweisbare Effekt im zweifaktoriellen Ansatz im Vergleich hinsichtlich der Worterkennung $(p=0,062)$. Jedoch bestätigte der zweifaktorielle Ansatz ein Effekt auf die Wortverständlichkeit durch die Kombinationen aus Zungenbeweglichkeit und Lokalisation $(p=0,010)$.

Ein Zustand nach Tracheostomie (WR=50,9 $\pm 17,9)$ ging mit einer schlechteren Wortverständlichkeit einher als Befunde ohne Tracheostoma (WR=59,4 $\pm 13,1$; $\mathrm{p}=0,040)$. Der Einfluss einer Radiatio auf die Sprechqualität war in dieser Studie nicht nachweisbar ( $W R=51,3 \pm 18,2$ für bestrahlte und $W R=57,1 \pm 15,4$ für nicht bestrahlte Patienten; $p=0,125)$. Das Rauchen hatte keine nachweisbaren Effekte auf die Verständlichkeit $(p=0,275)$.

\subsection{Die Ergebnisse der Hospital-Anxiety-and-Depression-Scale}

Für die festgelegten Cut-Offs von HADS Total $\geq 13$, HADS-A $\geq 7$ und HADS-D $\geq 5$ ergaben sich auffällige Werte mit 43,3\% für Totalscores, 43,3\% in den HADS-A-Subskalen und $51,1 \%$ in den HADS-D-Subskalen (Abb.3). Dies entsprach den erreichten Mittelwerten

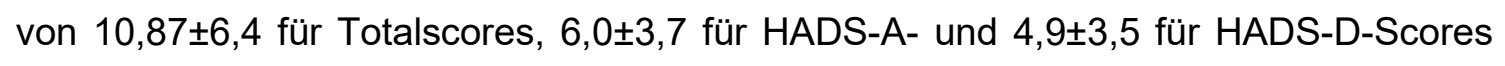
für das Gesamtkollektiv. 
Abb. 3: Cut-Offs überschreitende HADS-Werte: Verteilung innerhalb der Geschlechter in \%

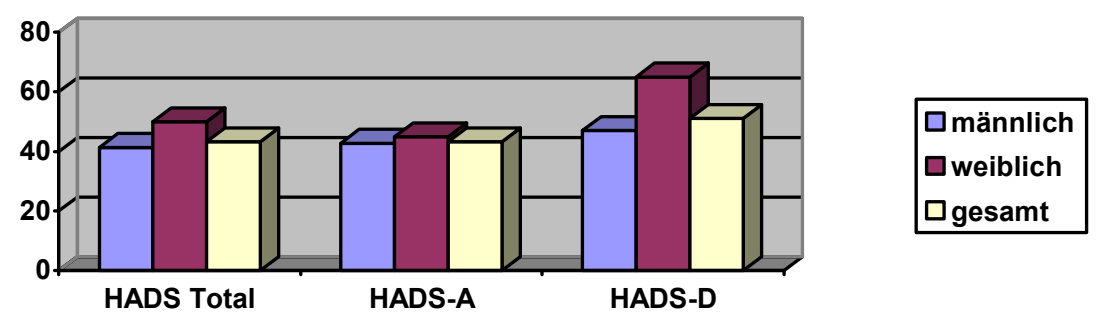

Soziodemographische Faktoren wie Alter, Geschlecht und Nikotinabusus standen in keinem Zusammenhang mit erhöhten Skalenwerten. Im Allgemeinen werden nur diskrete oder nur Einzelfälle betreffende Erhöhungen der HADS-Werte beobachtet. Dies betraf bei allen HAD-Skalen primär isolierte Größen wie die Tumorgröße für T3 (HADS-Total=13,7 $\pm 7,8$, HADS-A $=7,3 \pm 3,9$, HADS-D $=6,3 \pm 4,7$ ) und die Tumorlokalisation im Oberkiefer (HADS-Total=13,7 $\pm 3,3$, HADS-A=8,0 $\pm 2,6$, HADS$D=5,7 \pm 1,6$ ). Für die übrigen Tumorgrößen waren erhöhte Werte nur auf deskriptiver Ebene zu beobachten; für die Tumorlokalisationen waren sonst keine Auffälligkeiten in den HADS-Ergebnissen nachzuweisen. Alle weiteren Auffälligkeiten betrafen ausschließlich die HADS-D-Subskalen in deskriptiver Betrachtung. Mit leicht erhöhten Werten gingen einher: weibliche Teilnehmer $(5,6 \pm 3,5)$, Patienten mit der Tumorgröße T2 $(5,6 \pm 4,1)$, Patienten mit Scapula-/Parascapula- bzw. Fibulatransplantaten $(5,4 \pm 3,3)$ oder mit faszio-/myo-/kutanen $(5,1 \pm 4,0)$ und osteomyokutanen $(5,1 \pm 3,2)$ Transplantaten. Auch bei Patienten mit einem Zustand nach Tracheostoma $(5,1 \pm 3,6)$ und bei Probanden, die postoperativ mit dem Rauchen aufgehört hatten, zeigten sich leicht erhöhte HADS-D-Werte $(5,1 \pm 3,3)$.

\subsection{HADS und die Worterkennungsrate}

Es konnte ein schwacher negativer, signifikanter Zusammenhang zwischen der WR und den HADS-D-Scores (Spearman-Korrelation, $R=-0,247, p=0,019$ ) nachgewiesen werden. Ein statistisch nachweisbarer Zusammenhang zwischen HADS-Totalscores $(p=0,087)$ oder HADS-A-Scores $(p=0,518)$ und der WR bestand nicht.

\section{Diskussion und Ausblick}

Über die Funktionsverluste in der Artikulationsfähigkeit nach der operativen Tumorentfernung der Oropharynxmalignome wird vielfach diskutiert. Aus den Ergebnissen der beschriebenen Studie geht hervor, dass die soziodemographischen Größen für das untersuchte Kollektiv ein Jahr postoperativ weder hinsichtlich der Sprechverständlichkeit, noch im Auftreten von Ängstlichkeit oder Depressivität 
statistisch relevante Unterschiede zeigen. Eine bessere Worterkennungsrate bei Frauen wurde bereits von anderen Studien sowohl prä- als auch postoperativ belegt und zeigte in dieser Untersuchung keinen Zusammenhang zu kleineren Tumorgrößen $[37,41]$. Somit kann diese Feststellung nur eingeschränkt als prognostischer Faktor für das funktionelle Outcome im Patientenvergleich herangezogen werden.

Als tatsächlich ausschlaggebende Parameter kommen hier die morphologischen Einbußen als Therapiefolge in Betracht und es scheint von Bedeutung, die Umstände der Funktionsverluste genauer zu analysieren. Vor allem die Faktoren „Tumorgröße“, „Tumorlokalisation“, „Zungenbeweglichkeit“ und im Speziellen die Kombination „Tumorlokalisation und Zungenbeweglichkeit“ fielen in den Untersuchungen hinsichtlich der Wortverständlichkeit signifikant auf. Somit liegt die Vermutung nahe, dass die gewählten Operationsmethoden in Assoziation mit dem Grad der neoplasiebedingten Vorschädigung verständlicherweise einen entscheidenden Einfluss auf das funktionelle Outcome nehmen. Dies wird durch die Vergleiche zwischen einzelnen Parametern untermauert: lokalplastische Deckungen und Deckungen mit Ober-/ Unterarmtransplantaten allein kamen hauptsächlich bei kleineren Läsionen zum Einsatz, bedingten eine bessere Zungenmotilität und zeigten final geringere Verständlichkeitseinbußen. Bei größeren Defekten - vor allem in Verbindung mit Knocheninfiltration - waren entsprechend der Resektatgröße und -Morphologie ausgedehnte Strukturschädigungen $\mathrm{zu}$ versorgen, hier in vielen Fällen mit osteomyokutanen Transplantaten oder faszio-/myo-/kutanen Transplantaten in Verbindung mit freiem Os.

Die gewonnenen Erkenntnisse können den Behandlern wichtige Anhaltspunkte zur posttherapeutischen Artikulationsfähigkeit liefern - hier speziell als Teil des funktionellen Outcomes in Form von Sprechverständlichkeit und Zungenmotilität. Sie spiegeln das Ausmaß der Veränderung von morphologischen Strukturen wider und sollten bei Therapieentscheidungen berücksichtigt werden.

Die psychische Verfassung der Patienten im Verlauf der Therapie bildet eine variable Kenngröße. Sie wird als ein bedeutender Einflussfaktor für die Genesung der Betroffenen diskutiert. Auf das Auftreten von Angst und Depressionen bei Patienten mit Mundhöhlenkarzinomen im Verlauf der Erkrankung und Therapie wurde mehrfach hingewiesen [4, 32, 33, 53, 55-58, 62, 78, 80, 81]. Die Depressivität und Ängstlichkeit gehören in diesem Rahmen zu den am meisten vorkommenden psychischen Auffälligkeiten und kommen zu unterschiedlichen Zeitpunkten des Therapieverlaufes in unterschiedlicher Ausprägung vor. Zum Zeitpunkt der Untersuchung lagen Hinweise auf Zusammenhänge zwischen sprachlicher Kommunikationskompetenz und dem psychologischen Status der Mundhöhlenkarzinompatienten vor [50, 82, 83]. Einen 
Einstieg in diese Thematik bat eine laufende Untersuchung an gleichem Patientenkollektiv zu Wortverständlichkeit und bestehenden Zusammenhängen zu Bewältigungsstrategien. Es wurde belegt, dass negative Bewältigungsstrategien wie „Rumination“ und „Bedrohungsabwehr" sowie Bedarf nach Information und Erfahrungsaustausch mit niedrigerer Worterkennungsrate vergesellschaftet waren. Auch hier wurde auf eine mögliche Bedeutung von Depressivität hingewiesen und empfohlen, diese Thematik hinsichtlich der Worterkennung genauer zu untersuchen [37].

Somit sollte durch die vorliegende Arbeit geprüft werden, in welchem Ausmaß die Neigung zu Ängstlichkeit und Depressivität ein Jahr postoperativ noch mit der Sprechverständlichkeit in Verbindung steht. Die Ergebnisauswertung lieferte unter Anpassung der Cut-Off-Werte an die für die Patienten mit Tumoren im Kopf-HalsBereich validierten Skalenwerte tatsächlich einen Hinweis auf Zusammenhänge zwischen WR- und HADS-Werten, wie bereits durch einzelne Arbeitsgruppen vermutet [37, 42, 52, 78, 82]. Eine schlechtere Sprachverständlichkeit ging signifikant mit höheren Depressivitätsscores einher. Auch deskriptiv betrachtet zeigten einige HADSD-Werte auf einen möglichen Zusammenhang zum Ausmaß des operativen Umfangs. Auch die Symptome für Ängstlichkeit lagen auch noch ein Jahr postoperativ vor. Da für diese Faktoren jedoch keine Signifikanzniveaus nachgewiesen werden konnten, wurde hier auf zweifaktorielle Vergleiche hinsichtlich des WR-Outcomes verzichtet. Dennoch wäre hier potenziell ein Bereich vorhanden, der Basis für Untersuchungen mit einer größeren, statistisch erforderlichen Probandenzahl bietet. Unter anderem stellt sich dabei die Frage, inwieweit das funktionelle Endergebnis durch Beeinträchtigung der Sprechqualität die Depressionsmuster auslöst oder die psychologische Belastung direkt durch die Wahl der Defektdeckung unabhängig vom sprachlichen und Outcome getriggert wird. Im letzteren Fall wäre der Beteiligungsanteil der Parameter wie funktionelle Mastikations- und Schluckbeschwerden, Aspirationsprobleme und das ästhetische Endergebnis von gesondertem Interesse.

Ein schlechtes funktionelles Endergebnis kann nicht zuletzt auch umgekehrt durch eine vorhandene psychologische Verstimmung moduliert werden, indem sie die Motivation zur Behandlung beeinflusst und die rehabilitativen Maßnahmen erschwert. Die Wichtigkeit der affektiven Ebene für die Genesung der Patienten sollte zu keinem Zeitpunkt der Therapie vernachlässigt werden. Das Krankheitserleben setzt sich für den Patienten aus multiplen Einflüssen zusammen, die dabei gewählten Bewältigungsformen sind oft entscheidend für das Gelingen der kurativen und supportiven Maßnahmen [32, 33, 37, 62]. 
Das Hauptanliegen der Untersuchung ist es, den Therapeuten weitere Daten zu dem bereits umfangreichen Informationsspektrum über Folgen der Mundhöhlenkarzinomtherapie zu bieten, die im Idealfall der Anpassung der Maßnahmen zur psychoonkologischen Intervention dienen können. Neben der Nützlichkeit der Ergebnisse für die psychotherapeutischen Begleitmaßnahmen soll auch auf den potenziellen Wert der Daten im Rahmen der logopädischen Rehabilitation hingewiesen werden. Es sollte berücksichtigt werden, dass in der in dieser Arbeit genannten Literatur schwerpunktmäßig die Erkrankung als Ursache für die verschlechterte psychologische Verfassung der Patienten beschrieben und geringere Compliance mit schlechterem Therapie-Outcome in Verbindung gebracht wurden. In der vorliegenden Studie muss jedoch darauf hingewiesen werden, dass ein Jahr postoperativ in der Regel bereits die Erfolge der rehabilitativen und logopädischen Betreuung in die Ergebnisse der Erhebung mit einfließen können. Insoweit wären zusätzlich weitere Untersuchungen hinsichtlich der Effektivität dieser supportiven Maßnahmen auf die Sprechverständlichkeit und der Zusammenhänge zum psychologischen Zustand der Betroffenen von entscheidendem Interesse.

\section{Fazit}

Die Ergebnisse der Untersuchung zeigen, dass die Sprechfunktion im Zeitraum 12 bis 16 Monate nach der operativen Karzinomentfernung zum einen von der Tumor- und Therapieart abhängt, zeitgleich aber auch Zusammenhänge zur kognitiven Affektebene in Form von Ängstlichkeit und Depression zeigt. Neben den Maßnahmen zur Wiederherstellung der orofazialen Strukturen kann für ein möglichst gutes Gesamtergebnis neben der postoperativen Rehabilitation, den logopädischen Hilfsmaßnahmen auch eine psychoonkologische Betreuung der Betroffenen erforderlich sein. Die Nutzung der Techniken zur perioperativen Erfassung von Sprechqualität und psychoonkologisches Screening bilden dabei wertvolle Tools zur Ergebnisdokumentation und Verlaufskontrolle.

Die folgende Publikationsschrift ist ein Bestandteil dieser Studie und wurde zuerst veröffentlicht in der Fachzeitschrift Laryngo-Rhino-Otologie 2016 (Georg Thieme Verlag KG Stuttgart / New York): Sprechqualität und psychische Beeinträchtigung nach der Therapie von Mundhöhlentumoren / Speech Ability and Psychological Outcome After Treatment of Oral Cancer. N. Böhm, C. Knipfer, A. Maier, T. Bocklet, M. Rohde, F. W. Neukam, F. Stelzle, M. Schuster. Laryngo-Rhino-Otol 2016; 95(09): 610-619; DOI: $10.1055 / \mathrm{s}-0042-102256$. 


\section{Publikationsschrift}

\section{$\underline{6.1 \text { Zusammenfassung }}$}

\section{Hintergrund}

In den letzten Jahren werden vermehrt die Beziehungen zwischen operativer Tumortherapie und Inzidenz von Ängstlichkeit und Depressionen diskutiert. Diese prospektive Studie ist ein Vergleich zwischen der Einschränkung der Sprachverständlichkeit nach der Behandlung von Mundhöhlentumoren und der Anzeichen von Depressivität und Ängstlichkeit.

\section{Material und Methoden}

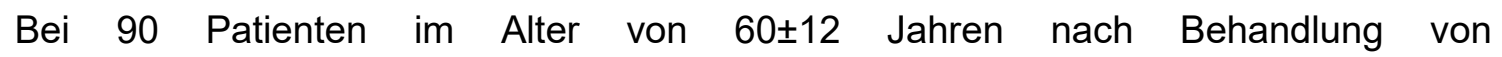
Mundhöhlenkarzinomen wurde ein Jahr postoperativ der Verständlichkeitsgrad standardisiert mittels automatischer Spracherkennung bestimmt (Worterkennungsrate, WR). Mögliche Anzeichen von Depressivität und Ängstlichkeit wurden mittels des Fragebogens Hospital-Anxiety-and-Depression-Scale (HADS) erfasst. Die Beziehungen zwischen WR und HADS und der Einflussgrößen wurden statistisch analysiert.

\section{Ergebnisse}

Der WR-Mittelwert lag bei 53,2 $\pm 17,2$. Der Unterschied in der WR zwischen den Tumorklassen T1 und T4 war signifikant. Frauen zeigten eine höhere WR als Männer. Weitere signifikante Unterschiede gab es bei WR-Vergleichen innerhalb der Gruppen „Tumorlokalisation“, „Transplantatentnahmestelle“, „Transplantatmorphologie“, „Zungenbeweglichkeitsgrade“ und „Tracheostoma“. Für die Zungenbeweglichkeit bestanden Interaktionen mit der Transplantatmorphologie, Transplantatentnahmeregion und Tumorlokalisation. Die HADS-Werte waren im Mittel erhöht: HADS-Total=43,3\%, HADS-A=43,3\% und HADS-D=51,1\%. Es bestand eine Korrelation für die WR mit den HADS-D-Scores, aber nicht mit den HADS-A-Scores.

\section{Schlussfolgerungen}

Kommunikationseinschränkungen nach chirurgischer Tumortherapie im Orofazialbereich können von dem Ausmaß der Behandlungsmaßnahmen abhängen und mit depressiver Beeinträchtigung im Zusammenhang stehen. Dies sollte im Rehabilitationskonzept beachtet werden. 


\subsection{Summary}

\section{Background}

In recent years interactions between surgical treatment of oral carcinoma and incidence of anxiety or depression have become a subject of discussions. This prospective study is a comparison between the extent of loss of speech intelligibility and presence of depressive symptoms or anxiety as a result of oral carcinoma.

\section{Material and Methods}

One year after surgical therapy for oral carcinoma, 90 patients of an average age of $60 \pm 12$ years were examined. Their speech intelligibility degree was measured using standardized automatic speech recognition (word recognition rate, WR). Symptoms of anxiety and depression were detected by use of HAD-Scales (HADS). Next to the relationship between WR and HADS other influential variables related to WR and HADS were statistically evaluated.

\section{Results}

The WR average was $53.2 \pm 17.2$. Female WR was better than male. The difference between tumor classifications T1 and T4 compared to the WR reached statistical significance. Significant differences were detected between WR and "tumor localization," "graft donor site," "graft morphology," "tongue motility," and "tracheostoma" groups. There was a relationship between tongue motility and graft morphology, graft donor site and tumor localization. HADS-Scores in the mean were elevated: HADS-Total $=43.3 \%$, HADS-A $=43.3 \%$ und HADS-D $=51.1 \%$. WR correlates with HADS-D-Subscale, but not with HADS-A-Subscale.

\section{Conclusion}

Communication disorders as a result of neoplasmic orofacial surgery may be related to extent of the treatment and to affective impairments. This should receive attention in the concept of rehabilitation. 


\subsection{Einleitung}

Eine gesunde Mundhöhle gewährt lebensnotwendige Funktionen wie die Nahrungsaufnahme und stellt eines der wichtigsten Systeme des menschlichen Körpers dar [1]. Dabei ist die Fähigkeit der Artikulation und die Ästhetik zur Erhaltung der sozialen Integrität nicht zu vernachlässigen [2-4]. Die operative Therapie der Malignome im Mund-Rachen-Bereich, oft in Verbindung mit neoadjuvanter oder adjuvanter Radiochemotherapie, führt in vielen Fällen zu senso-motorischen Funktionseinbußen. Dazu gehören die eingeschränkte Beweglichkeit, die Sensibilitätsstörungen, der Verlust von Geschmacks- und Geruchssinn und folglich die erschwerte orale Rehabilitation [5-8]. Daraus resultieren nicht selten eine Verschlechterung der Kau- und Schluckfunktion, der Sprechfähigkeit und damit der Verständlichkeit [1, 3, 6, 7, 9-15]. Die meist durchgeführte primär chirurgische Therapie beinhaltet daher auch Maßnahmen, die der Wiederherstellung der Nahrungsaufnahme und des Sprechens dienen (Rekonstruktion von Knochen- und Weichgewebe, Eingliederung von Obturatoren, Implantaten und Zahnersatz) [8, 16, 17].

Sprechprobleme nach chirurgischer Tumortherapie bilden nach aktueller Literaturlage eine der größten Funktionseinschränkungen. Diese treten bei circa zwei Drittel der Patienten auf und bleiben auch ein Jahr postoperativ noch bei über einem Drittel bestehen [9, 10, 12, 18]. Weibliche Patienten zeigen in bisherigen Untersuchungen einen besseren Verständlichkeitsgrad als männliche $[3,9]$. Während die Verständlichkeit bei Gesunden mit zunehmendem Alter leicht abnimmt, zeigt sich diese Altersabhängigkeit bei Tumorpatienten nicht [14]. Die Verständlichkeit büßt aber mit zunehmender Tumorausdehnung und der damit einhergehenden Resektionsvolumina an Qualität ein [3, 6, 7, 11, 15]. Dabei resultieren aus lokalplastischer Deckung (entsprechend meist bei kleineren Tumoren) eher weniger Sensibilitäts- oder Motilitätsstörungen der Zunge und umgebender Gewebe als bei freien mikrovaskulär anastomosierten Transplantaten [7, 9, 12, 15]. Auch die Lokalisation eines Mundhöhlenkarzinoms zeigt in früheren Untersuchungen einen Einfluss auf die Sprechqualität: Tumore im Mundbodenbereich oder mit Beteiligung des Unterkieferalveolarkammes gehen mit schlechterer Sprachverständlichkeit einher als Mundhöhlenkarzinome an anderen Lokalisationen [9, 11, 15]. Größere Auswirkungen auf die Qualität des Sprechens kann auch eine adjuvante Radiotherapie haben [8, 9, 15], wobei man diesen Effekt bei kleineren Tumoren nicht belegen kann [7].

Die Funktionstüchtigkeit des operierten Bereiches, das ästhetische Endergebnis und die damit verbundene Lebensqualität können eine wichtige Rolle für die stabile geistige Verfassung nach einem chirurgischen Eingriff spielen [1, 2, 4]. Aber auch bereits die Diagnosestellung "Malignom“ und die Konfrontation des Patienten mit diesem 
Krankheitsbild können bei Betroffenen psychische Einschnitte zur Folge haben [19]. Patienten können mit Passivität, Depressivität, sozialem Rückzug und Resignation reagieren [2, 20, 21-23]. Dabei zählen Depressivität und Ängstlichkeit zu den häufigsten psychischen Auffälligkeiten [23, 24]. Zu Angst und Depressivität liefert die Literatur bei Tumorpatienten zum Teil widersprüchliche Ergebnisse. Die Ängstlichkeit scheint vor allem bei Diagnosestellung, vor dem chirurgischen Eingriff und vor der radioonkologischen Therapie am höchsten zu sein und danach abzunehmen [4, 21, 25, 26]. Die Depression tritt hingegen stets im Verlauf der chirurgischen oder nach der radioonkologischen Therapie in hoher Ausprägung auf [21, 26, 27]. Die Art, Größe der Neoplasie und ihre Lokalisation sind dabei für das subjektive Krankheitserleben eher von nachgeordneter Bedeutung [4, 6, 21, 28], wobei eine zunehmende Tumorgröße durchaus tendenziell vermehrt mit Symptomen einer Depression einhergehen kann [21]. Bereits in Normkollektiven weisen Frauen im Vergleich zu Männern mehr Angstund Depressionssymptome auf [29]. Bei Patienten nach Tumortherapie im KopfHalsbereich werden im Geschlechtervergleich höhere Werte bei Frauen für Angst beschrieben [21, 22, 23]. Bei Frauen werden mehr emotionale Belastungen, bei Männern eher schlechtere Lebensqualität erwähnt [4, 28]. Jüngere Patienten zeigen mehr ängstliche Symptome als ältere [21, 22]. Es sind Zusammenhänge von Rauchverhalten bezüglich Leidensdruck, Zigarettenkonsum und Rezidivängsten beschrieben, die Raucher als eine Risikogruppe für psychische Anfälligkeit darstellen [30]. Entsprechend einer Studie an laryngektomierten Patienten hingegen sollen Raucher nicht wesentlich mehr Angst vor einer Krebserkrankung haben [31].

Somit sind nach aktueller Studienlage bereits viele Einzelaspekte zur Ergebnisqualität des Sprechens und dem emotionalen Outcome nach der Behandlung von Malignomen im Kopf-Hals-Bereich untersucht worden. Aufgrund von unterschiedlichen Schwerpunktsetzungen dieser Arbeiten lässt sich bisher aber nicht immer eindeutig belegen, inwieweit diese für das jeweilige Outcome wichtigen Aspekte durch die Erkrankung und ihre Therapie kausal bedingt werden. Ebenso fehlen Untersuchungen zu therapiebezogenen Faktoren, die eine Aussage über Wechselwirkungen zwischen qualitativ objektiv und quantitativ erfassten Daten zur Sprechqualität und Ängstlichkeit beziehungsweise Depressivität erlauben.

Die vorliegende Studie untersucht deshalb den Zusammenhang zwischen der Einschränkung der Verständlichkeit, also der Qualität des Sprechens, und emotionalen Beeinträchtigungen hinsichtlich der Symptome von Ängstlichkeit und Depressivität der Betroffenen. Die Haupthypothese ist dabei, dass eine niedrige Sprachverständlichkeit eine gravierende Kommunikationseinschränkung darstellt, die in negativem Zusammenhang mit dem emotionalen Befinden steht. Weitere untersuchte Hypothesen 
sind, dass noch weitere Beziehungen zwischen der Sprechqualität und der emotionalen Verfassung bestehen: zum Alter, Geschlecht, Tumorlokalisation, Tumorgröße, Rekonstruktionsart und der daraus resultierenden Zungenbeweglichkeit sowie zum Rauchen. Es wird vor allem angenommen, dass höheres Alter, größere Resektionsvolumina und stärkere Bewegungseinschränkungen der Zunge mit schlechterer Sprachverständlichkeit einhergehen. Zugleich wird untersucht, ob die genannten Größen mit höheren HADS-Scores verbunden sind.

\subsection{Patienten und Methoden}

Die Studie erfolgte monozentrisch im Rahmen der Tumornachsorgesprechstunde und wurde durch die Ethikkommission der Universität Erlangen-Nürnberg unter Beachtung der Helsinki-Deklaration 1975 (1983) genehmigt (Antragsnummer 3732). Die Teilnahme war freiwillig und konnte jederzeit ohne Angaben von Gründen widerrufen werden. Eine Vergütung bei Teilnahme erfolgte nicht. Die Einschlusskriterien für die Patientenauswahl waren histologisch gesicherte Befunde mit Plattenepithelkarzinomen der Mundhöhe, deren primär chirurgische Versorgung mit Rezidivfreiheit zum gewählten Untersuchungszeitpunkt 12 bis 16 Monate zurücklag. Um eventuelle Abweichungen oder Ergebnisverfälschungen bei dem Vergleich der Sprechqualität auszuschließen, wurden in dieser Studie nur Patienten mit deutscher Muttersprache betrachtet. Die erhobenen Daten beinhalten Angaben (nach Aktenlage) zum Alter, Geschlecht, Ausmaß der Erkrankung wie Tumorgröße, Lokalisation und der Therapiemethoden. Die Daten über das Durchlaufen einer logopädischen Therapie oder Rehabilitationsbehandlung, die konzeptionell nicht in der gleichen Einrichtung stattfanden, waren nicht ausreichend dokumentierbar. Die Rehabilitationsmaßnahmen waren, wenn stattgefunden, sehr individualisiert und sowohl schwerpunktmäßig als auch zeitlich oft unterschiedlich gestaltet. Da zu der untersuchten Gruppe aufgrund der Angabenheterogenität keine sinnvolle statistische Analyse möglich war, fanden die Daten zur Rehabilitation keine Berücksichtigung.

Im direkten Patientengespräch wurden folgende Erhebungsmethoden eingebunden: die Messung des Grads der Verständlichkeit mittels akustisch-stochastischer Analyse des Sprechens, die Evaluation von ängstlichen und depressiven Auffälligkeiten mit etabliertem Fragebogen zur Selbsterhebung und das Erfassen der Daten zum Rauchverhalten. Die Zungenbeweglichkeit wurde visuell durch einen erfahrenen Arzt erfasst und in drei Gruppen eingeteilt. Der Gruppe I wurden Patienten ohne bzw. mit nur geringfügiger Einschränkung in vertikaler und bzw. oder horizontaler Richtung zugeordnet. In Gruppe II wurden Patienten mit mittlerer und in Gruppe III mit starker Bewegungseinschränkung einbezogen. Eine Übersicht über die klinischen Parameter 
ist in der Tabelle 1 zusammengefasst. Anschließend erfolgte ein statistischer Vergleich der Werte der Sprechqualität der untersuchten Patienten und der Fragebogenergebnisse hinsichtlich gleicher Einflussparameter - Tumorgröße, Geschlecht, Alter und Rauchverhalten. Es wurden darüber hinaus die Art der Defektdeckung, die Zungenbeweglichkeit, die Durchführung einer Strahlentherapie und das Vorhandensein eines Tracheostoma berücksichtigt.

\subsection{Testmaterial und Durchführung}

\subsubsection{Spracherkennungssystem}

Die Funktionsbeeinträchtigung hinsichtlich des Sprechens nach der Therapie wurde mittels rechnergestützter Sprachanalyse erfasst. Mit den Patienten wurden digitalisierte Sprachaufnahmen angefertigt, die mittels eines Spracherkennungsprogramms objektiv ausgewertet und auf akustische Übereinstimmung zu Modellwörtern überprüft wurden [32]. Das genutzte Programm wurde zur Erkennung und Analyse von Stimm- und Sprechstörungen entwickelt und bereits mehrmals erfolgreich im Rahmen von Verständlichkeitsuntersuchungen eingesetzt [3, 5, 7, 11-15, 33, 34]. Dabei wird die so genannte Worterkennungsrate (WR) als Grad für die Verständlichkeit berechnet. Dieser gibt den Prozentsatz aller in einem vorgegebenen Standardtext durch das Programm als korrekt erkannter Wörter an und lässt sich aus folgender Formel berechnen: $\mathrm{WR}[\%]=100$ * NC / N. Dabei stehen die Variablen NC für die Anzahl der korrekt erkannten Worte und $\mathrm{N}$ für die Anzahl aller gesprochenen Worte des gelesenen Textes [32]. Der WR-Wert bei gesunden und sprachlich uneingeschränkten Personen liegt bei $76 \pm 7 \%[7,13,14]$. Als Referenzsprachwerte dienen dabei 27 Stunden transkribierter Sprache eines gesunden Kollektivs [32]. Die dabei durch das Programm ermittelte Sprachverständlichkeit entspricht in hohem Maß den Ergebnissen von Zuhörergremien [13, 14]. Die Testpersonen wurden gebeten, zur Aufnahme den Text "Nordwind und Sonne" langsam und deutlich vorzulesen. Die Fabel, bestehend aus 108 Wörtern, beinhaltet alle Phoneme der deutschen Sprache. Die Aufzeichnungen wurden digital durchgeführt; dazu wurde ein Nachbesprechungsmikrophon dnt Call $4 U$ Comfort-Headset (DNT GmbH, Dietzenbach, Abtastfrequenz 16kHz, Auflösung 16 Bit) genutzt.

\subsubsection{Fragebögen}

Zur Feststellung von Ängstlichkeit und Depressivität wurde die deutsche Ausgabe des HADS-Fragebogens genutzt (Hospital Anxiety and Depression Scale, HADS) [35]. Diese gilt als ein gut validiertes Instrument für Screeningzwecke von Angststörungen 
bzw. Depressionen und findet aufgrund von hoher Sensitivität und Spezifität breite Verwendung in der Psychoonkologie [29, 36, 37]. Der Fragebogen teilt sich in 2 Subskalen (HADS-A für Angst und HADS-D für Depressionen), die jeweils 7 Fragen beinhalten. Die jeweiligen Antwortmöglichkeiten erlauben eine Abstufung der Werte zwischen 0 und 3 . Höhere Punktzahlen stehen für ängstliche oder depressive Symptome. In jeder Subskala können maximal 21 Punkte erreicht werden. Werte bis zu 7 Punkten pro Skala gelten als unauffällig. Punktwerte von 8 bis 10 werden als grenzwertig und ab 11 als auffällig eingestuft. Der einfache Aufbau des Fragebogens und der geringe zeitliche Aufwand zum Ausfüllen der Items erhöhen zusätzlich die Akzeptanz dieser Screeningmethode durch den Patienten.

In der vorliegenden Studie wurden die Cut-Off-Werte für HADS-Totalscores bei $\geq 13$, für HADS-A bei $\geq 7$ und für HADS-D bei $\geq 5$ gesetzt. Die Anwendung dieser Grenzwerte wurde bereits an Patienten mit Malignomen im Kopf-Halsbereich erprobt und wird aufgrund der höchstmöglichen Balance zwischen der Sensibilität und der Spezifität des Testverfahrens empfohlen. Für die gewählten Cut-Off-Werte werden die Sensitivität und Spezifität für HADS-A jeweils mit 0,82 und 0,49, für HADS-D jeweils mit 0,75 und 0,65 angegeben. Die Werte für HADS-Totalscores liegen jeweils bei 0,76 und $0,60[38,39]$.

\subsubsection{Statistische Methoden}

Quantitative Größen wurden anhand von Mittelwert und Standardabweichung, Minimum und Maximum sowie den Quartilen beschreibend dargestellt und mittels Kolmogorov-Smirnov-Test bzw. bei kleinen Fallzahlen mit dem Shapiro-Wilk-Test auf Normalverteilung geprüft. Bei signifikanten Abweichungen von einer Normalverteilung erfolgte der Vergleich zweier unabhängiger Stichproben mit dem U-Test, der Vergleich von mehr als zwei unabhängigen Stichproben mit dem Kruskal-Wallis-Test. Zeigte sich keine signifikante Abweichung von einer Normalverteilung, so wurden anstelle oben genannter Tests der t-Test für unabhängige Stichproben oder eine Varianzanalyse (ANOVA) eingesetzt. Um Zusammenhänge zwischen den hier untersuchten quantitativen Parametern zu prüfen, wurden Korrelationsanalysen nach Spearman im nicht-parametrischen Fall oder nach Pearson im parametrischen Fall durchgeführt. Es wurde zweiseitig getestet und ein Signifikanzniveau von 5\% zugrunde gelegt. Für die Durchührung der statistischen Berechnungen wurde IBM SPSS Statistics 22 (SPSS Inc. an IBM Company, Chicago, IL) eingesetzt. 


\section{$\underline{6.6 \text { Ergebnisse }}$}

\subsubsection{Stichprobendaten}

An der Untersuchung nahmen 97 Personen teil (76 männlich und 21 weiblich). Davon erfüllten 90 Patienten - 70 männlich (77,7\%) und 20 (22,2\%) weiblich - die Einschlusskriterien. Alle erfragten Parameter konnten vollständig erhoben werden. Der allgemeine Altersdurchschnitt der ausgewerteten Stichprobe lag bei $60 \pm 12$ Jahren. Es lagen Tumorgrößen T1 bis T4 mit Tumorlokalisationen im Mundboden, Zunge, Oberkiefer und Unterkiefer vor. Die entstandenen Defekte wurden lokalplastisch oder mit freien mikrovaskulär gestielten Transplantaten gedeckt. Es kamen freie Ober-/ Unterarmtransplantate und freie Scapula-/Parascapula- bzw. Fibulatransplantate zum Einsatz. Morphologisch gesehen waren diese faszio-/myo-/kutan, faszio-/myo-/kutan in Verbindung mit freiem Knochentransplantat oder osteomyokutan zusammengesetzt. Genauere Angaben zur prozentualen und geschlechtsspezifischen Verteilung sind zusammen mit den Daten zu Strahlentherapie, Tracheostomie, Nikotinabusus und Zungenbeweglichkeit in der Tabelle 1 zusammengefasst. 
Tabelle 1: Stichprobenbeschreibung. Insgesamt 90 Patienten, 70 männlich, 20 weiblich.

\begin{tabular}{|c|c|c|c|c|c|c|}
\hline & männlich & $\%$ & weiblich & $\%$ & gesamt & $\%$ \\
\hline \multicolumn{7}{|c|}{ 1a. Klinische Parameter mit Verteilungen innerhalb der Geschlechter } \\
\hline \multicolumn{7}{|l|}{ Alter } \\
\hline Durchschnitt + StAbw & $58 \pm 10$ & - & $68 \pm 15$ & - & $60 \pm 12$ & - \\
\hline \multicolumn{7}{|l|}{ Tumorgröße } \\
\hline $\mathrm{T} 1$ & 29 & 41,4 & 10 & 50,0 & 39 & 43,3 \\
\hline T2 & 13 & 18,6 & 3 & 15,0 & 16 & 17,8 \\
\hline T3 & 7 & 10,0 & 2 & 10,0 & 9 & 10,0 \\
\hline T4 & 21 & 30,0 & 5 & 25,0 & 26 & 28,9 \\
\hline \multicolumn{7}{|l|}{ Tumorlokalisation } \\
\hline Mundboden & 30 & 42,9 & 7 & 35,0 & 37 & 41,1 \\
\hline Zunge & 22 & 31,4 & 6 & 30,0 & 28 & 31,1 \\
\hline Oberkiefer & 6 & 8,6 & 1 & 5,0 & 7 & 7,8 \\
\hline Unterkiefer & 12 & 17,1 & 6 & 30,0 & 18 & 20,0 \\
\hline \multicolumn{7}{|l|}{ Nikotinabusus } \\
\hline nein & 17 & 24,3 & 17 & 85 & 34 & 37,8 \\
\hline vor OP & 33 & 47,1 & 3 & 15 & 36 & 40 \\
\hline vor und nach OP & 20 & 28,6 & 0 & 0 & 20 & 22,2 \\
\hline \multicolumn{7}{|c|}{ 1b. Therapiemaßnahmen mit Verteilungen innerhalb der Geschlechter } \\
\hline Radiatio & 49 & 70,0 & 15 & 75,0 & 64 & 71,1 \\
\hline Tracheostoma & 47 & 67,1 & 14 & 70,0 & 61 & 67,8 \\
\hline Freies Transplantat & 54 & 77,1 & 13 & 65,0 & 66 & 73,3 \\
\hline \multicolumn{7}{|c|}{ Transplantatentnahmestelle } \\
\hline lokalplastisch* & 16 & 22,9 & 7 & 35,0 & 23 & 25,6 \\
\hline Oberarm / Unterarm ${ }^{\star *}$ & 29 & 41,4 & 8 & 40,0 & 37 & 41,1 \\
\hline Scapula / Parascapula** & 25 & 35,7 & 5 & 25,0 & 30 & 33,3 \\
\hline \multicolumn{7}{|c|}{ Transplantatmorphologie } \\
\hline faszio-/myo-/kutan & 30 & 42,8 & 8 & 40,0 & 38 & 42,2 \\
\hline faszio-/myo-/kutan + os & 3 & 4,9 & 1 & 5,0 & 4 & 4,4 \\
\hline osteomyokutan & 21 & 30,0 & 4 & 20,0 & 25 & 27,8 \\
\hline \multicolumn{7}{|c|}{ 1c. Postoperative Zungenbeweglichkeit } \\
\hline Gruppe I & 34 & 48,6 & 9 & 45,0 & 43 & 47,8 \\
\hline Gruppe II & 24 & 34,3 & 6 & 30,0 & 30 & 33,3 \\
\hline Gruppe III & 12 & 17,1 & 5 & 25,0 & 17 & 18,9 \\
\hline \multicolumn{7}{|c|}{ 1d. HADS: Werte oberhalb von Cut-Offs und deren Häufigkeiten innerhalb der Geschlechter } \\
\hline HADS Total $(\geq 13)$ & 29 & 41,4 & 10 & 50,0 & 39 & 43,3 \\
\hline HADS-A $(\geq 7)$ & 30 & 42,8 & 9 & 45,0 & 39 & 43,3 \\
\hline HADS-D ( $\geq 5)$ & 33 & 47,1 & 13 & 65,0 & 46 & 51,1 \\
\hline
\end{tabular}

* lokale gestielte Gewebeplastik

** freies mikrovaskulär reanastomosiertes Transplantat 


\subsubsection{Sprachverständlichkeit und ihre Beziehungen zu anderen Parametern}

\subsubsection{WR-Mittelwerte und Ergebnisse des Spracherkennungssystems}

Der WR-Mittelwert lag bei 53,2 $\pm 17,2$. Die Ergebnisse des automatischen Spracherkennungssystems werden in Tabelle 2 dargestellt.

Tabelle 2: Sprechverständlichkeit (WR) - Mittelwerte innerhalb der untersuchten Gruppen

\begin{tabular}{|c|c|c|}
\hline $\begin{array}{l}\text { Sprechverständlichkeit } \\
\text { (WR) }\end{array}$ & WR-Mittelwert & $\begin{array}{l}\text { Standardabweic } \\
\text { hung }\end{array}$ \\
\hline Gesamtstichprobe & 53,2 & 17,2 \\
\hline \multicolumn{3}{|l|}{ Tumorgröße } \\
\hline $\mathrm{T} 1$ & 60,3 & 15,6 \\
\hline T2 & 50,6 & 13,1 \\
\hline T3 & 52,2 & 16,7 \\
\hline $\mathrm{T} 4$ & 45,1 & 17,2 \\
\hline \multicolumn{3}{|l|}{ Geschlecht } \\
\hline männlich & 51,3 & 18,2 \\
\hline weiblich & 60,6 & 15,0 \\
\hline \multicolumn{3}{|l|}{ Tumorlokalisation } \\
\hline Mundboden & 51,5 & 13,6 \\
\hline Zunge & 50,0 & 12,9 \\
\hline Oberkiefer & 34,9 & 15,3 \\
\hline Unterkiefer & 49,0 & 13,1 \\
\hline \multicolumn{3}{|l|}{ Nikotinabusus } \\
\hline nein & 56,9 & 17,8 \\
\hline vor OP & 50,3 & 17,4 \\
\hline vor und nach OP & 52,1 & 16,2 \\
\hline \multicolumn{3}{|l|}{ Radiatio } \\
\hline ja & 51,3 & 18,2 \\
\hline nein & 57,1 & 15,4 \\
\hline \multicolumn{3}{|l|}{ Tracheostoma } \\
\hline ja & 50,9 & 17,9 \\
\hline nein & 59,4 & 13,1 \\
\hline \multicolumn{3}{|c|}{ Transplantatentnahmestelle } \\
\hline lokalplastisch* & 60,0 & 16,9 \\
\hline Oberarm / Unterarm* & 56,3 & 13,6 \\
\hline Scapula / Parascapula** & 44,1 & 18,1 \\
\hline \multicolumn{3}{|l|}{ Transplantatmorphologie } \\
\hline faszio-/myo-/kutan & 54,6 & 15,3 \\
\hline faszio-/myo-/kutan + os & 32,6 & 22,4 \\
\hline osteomyokutan & 48,1 & 16,4 \\
\hline \multicolumn{3}{|l|}{ Zungenbeweglichkeit } \\
\hline Stufe I & 60,9 & 14,0 \\
\hline Stufe II & 51,4 & 15,4 \\
\hline Stufe III & 36,7 & 15,8 \\
\hline
\end{tabular}

* lokale gestielte Gewebeplastik

** freies mikrovaskulär reanastomosiertes Transplantat 


\subsubsection{Soziodemographische Parameter: Alter, Geschlecht und Nikotinabusus}

Es zeigte sich kein Zusammenhang zwischen dem Alter und der WR (PearsonKorrelation, $R=-0,058, p=0,590)$. Beim Vergleich der Geschlechter hinsichtlich der WR hatten die Patientinnen eine signifikant höhere WR als die männlichen Probanden (tTest für unabhängige Stichproben, $p=0,029)$. Zwischen dem Nikotinabusus und der WR konnten keine signifikanten Wechselwirkungen nachgewiesen werden (ANOVA, $p=0,275)$.

\subsubsection{Tumorcharakteristika und Therapiemodalitäten}

Es zeigte sich ein signifikanter Unterschied zwischen den Tumorgrößen in Bezug auf die WR (ANOVA, $p=0,013$ ), allerdings ließ dieser sich nur zwischen den Tumorklassen T1 und T4 nachweisen (Post-Hoc-Paarvergleiche mittels Bonferroni-korrigierten tTests, $p=0,009$; alle übrigen Tumorklassen $p>0,05$ ). Es konnte ein signifikanter Unterschied zwischen den Tumorlokalisationen hinsichtlich der WR nachgewiesen werden (ANOVA, $p=0,003$ ).

Weitere mit einer veränderten Sprachverständlichkeit verbundene Parametergruppen waren die Transplantatentnahmeregion, die Transplantatmorphologie und die Zungenbeweglichkeit. Signifikante Unterschiede in der WR gab es im Vergleich zwischen lokalplastischer Deckung mit freiem Scapula-/Parascapula- bzw. Fibulatransplantat ( $U$-Test, $p=0,001)$ und freiem Ober-/Unterarmtransplantat mit freiem Scapula-/Parascapula- bzw. Fibulatransplantat (U-Test, $p=0,003$ ). Die Betrachtung nach morphologischen Kriterien ergab signifikante WR-Unterschiede bei paarweisen Vergleichen zwischen lokalplastischer Deckung mit faszio-/myo-/kutanem Transplantat in Verbindung mit freiem Knochentransplantat ( $U$-Test, $p=0,022)$, lokalplastischer Deckung mit osteomyokutanem Transplantat (U-Test, $p=0,006)$ und faszio-/myo-/ kutanem Transplantat mit faszio-/myo-/kutanem Transplantat in Verbindung mit freiem Knochentransplantat (U-Test, $p=0,049)$. Dabei musste bei der letzten Gruppe die kleine Fallzahl von vier Patienten berücksichtigt werden, somit hatte dieser Vergleich einen eher explorativen Charakter.

Es zeigte sich für die gesamte Stichprobe ein signifikanter Unterschied zwischen den Zungenbeweglichkeitsgruppen hinsichtlich der Worterkennungsrate (ANOVA, $p<0,001)$. Dabei erzielten die Patienten einer geringeren Einschränkung der Zungenbeweglichkeit signifikant höhere WR-Werte als die Patienten mit einer stärkeren Motilitätseinschränkungen (Scheffé-Test; Stufe I verglichen mit Stufe II bei $p=0,030$, Stufe I mit Stufe III bei $p<0,001$ und Stufe II mit Stufe III bei $p=0,007$ ). Auch zwischen der Transplantatmorphologie und der Zungenbeweglichkeit zeigten sich ein 
signifikanter Zusammenhang (Chi-Quadrat-Test auf linearen Trend, $p<0,001$ ). Im Vergleich zwischen den bestrahlten und den nicht bestrahlten Patienten ließ sich kein signifikanter Unterschied in den erzielten WR-Ergebnissen nachweisen (U-Test, $p=0,125)$. Patienten mit einem Tracheostoma in der Vorgeschichte hatten eine signifikant niedrigere WR als Patienten, die keines hatten (t-Test für unabhängige Stichproben, $p=0,040$ ).

\subsubsection{Multivariate Analysen}

a) WR hinsichtlich Tumorgröße und Geschlecht

Ein Zusammenhang zwischen Tumorgröße und Geschlecht konnte nicht nachgewiesen werden (Chi-Quadrat-Test auf linearen Trend, $p=0,496$ ). Hinsichtlich der WR fiel hier der Unterschied zwischen den Geschlechtern nicht signifikant aus (zweifaktorielle ANOVA, $p=0,147$ ), wohl aber zwischen den Tumorgrößen: diese unterschieden sich signifikant in der WR $(p=0,002)$. Ein signifikanter Effekt der Kombination aus Geschlecht und Tumorgröße auf die WR konnte nicht nachgewiesen werden, signifikante Interaktionen dieser beiden Parameter zeigten sich nicht $(p=0,317)$.

b) WR hinsichtlich Zungenbeweglichkeit und Tumorcharakteristika / Therapiemodalitäten

Die Stufen der Zungenbeweglichkeit unterschieden sich signifikant bezüglich der WR (zweifaktorielle ANOVA, p<0,001). Es konnte gezeigt werden, dass die Kombination aus Zungenbeweglichkeit und Lokalisation einen signifikanten Effekt auf die WR hat $(p=0,010)$. Dabei erwiesen sich die Tumorlokalisationen als signifikant unterschiedlich hinsichtlich der erzielten WR (ANOVA, $p=0,003$ ). Auch für die Kombination aus Zungenbeweglichkeit und Transplantatentnahmeregion zeigten sich signifikante Wechselwirkungen (ANOVA, $p=0,025$ ). Dabei war aber im zweifaktoriellen Ansatz der Effekt der Transplantatentnahmeregion auf die WR nicht mehr signifikant (ANOVA, $p=0,062$ ). Auch zwischen den Morphologiegruppen konnten für die gesamte Stichprobe im Vergleich hinsichtlich der WR keine signifikanten Unterschiede mehr festgestellt werden (ANOVA, $p=0,292$ ). Es waren auch keine signifikanten Effekte mehr auf die WR durch die Kombination „Zungenbeweglichkeitsgrade und Transplantatmorphologie“ zu verzeichnen (ANOVA, $p=0,167$ ).

Für einen zweifaktoriellen Ansatz zur Überprüfung von Effekten der Kombinationen „Tumorgröße“ (Faktor 1) und „Lokalisation“/ „Spenderregion“/ „Morphologie“ (Faktor 2) auf die WR waren die Größen der entstandenen Fallgruppen zu klein. 


\subsection{3 Ängstlichkeit, Depressivität und Einflussgrößen}

\subsubsection{Die Ergebnisse des HADS-Fragebogens}

Der Mittelwert der HADS-Scores für das gesamte Patientenkollektiv lag bei $10,87 \pm 6,4$

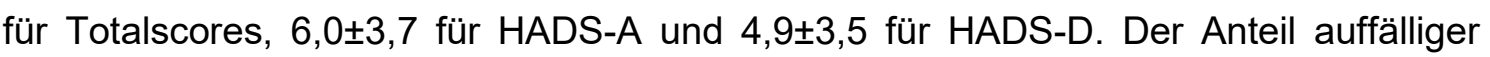
HADS-Totalscores (Scores $\geq 13$ ) betrug 43,3\%. Der Anteil auffälliger HADS-Werte für Ängstlichkeit (Scores $\geq 7$ ) lagen bei $43,3 \%$ und für Depressionen (Scores $\geq 5$ ) bei $51,1 \%$. Die Angaben zur prozentualen und geschlechtsspezifischen Verteilung sind in der Tabelle 1 (Teil 1d) zusammengefasst.

Bezüglich der HADS zeigen sich folgende Auffälligkeiten: Bei T3 überschritten beide Skalen und der Totalscore diskret die festgelegten Cut-Off-Werte (Mittelwerte für HADS-Total=13,67, für HADS-A=7,33 und für HADS-D=6,33). Die Tumorlokalisation im Oberkiefer geht ebenfalls mit geringfügigen Überschreitungen aller Cut-Off-Werte einher (Durchschnittswerte für HADS-Total=13,71, für HADS-A=8,00 und für HADS$D=5,71)$. Da sich diese Gruppe auf insgesamt nur sieben Fälle beschränkt, wurden die Ergebnisse hier als eher tendenziell eingestuft. Im Weiteren waren leicht erhöhte Werte ausschließlich für HADS-D festzustellen. Dies betraf die weiblichen Teilnehmer $(5,6 \pm 3,5)$, die Tumorgröße T2 $(5,6 \pm 4,1)$, Patienten mit freien Scapula-/Parascapula-

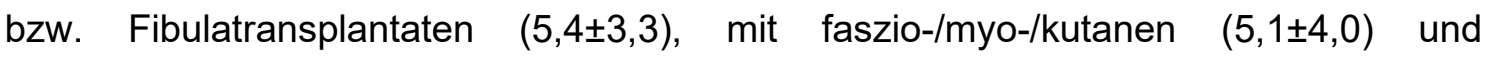
osteomyokutanen $(5,1 \pm 3,2)$ Transplantaten und Patienten mit ein Tracheostoma in der Anamnese $(5,1 \pm 3,6)$. Bei Teilnehmern, die postoperativ das Rauchen eingestellt hatten, waren die HADS-D-Werte ebenfalls leicht erhöht $(5,1 \pm 3,3)$.

\subsubsection{Soziodemographische Parameter: Alter, Geschlecht und Nikotinabusus}

Hinsichtlich der HAD-Skalen konnte kein Zusammenhang mit dem Alter (SpearmanKorrelation, $R<0,2, p>0,05$, für Totalscores und Subskalen) oder dem Geschlecht (UTest, $p=0,400$ ) nachgewiesen werden. Auch zwischen den drei Patientengruppen, die den Nikotinabusus charakterisieren, bestand kein signifikanter Unterschied (KruskalWallis-Test, HADS Total: $p=0,438$ ).

\subsubsection{Tumorcharakteristika und Therapiemodalitäten}

Zwischen den Tumorgrößen T1 bis T4 und den HAD-Skalen fielen keine signifikanten Verteilungsunterschiede auf (Kruskal-Wallis-Test, HADS Total: p=0,271). Im deskriptiven Vergleich wurde jedoch deutlich, dass die Tumorgrößen T2 und T3 eine höhere Streuung mit einer Tendenz zur Zunahme bei den Scores aufwiesen. Es lag auch insgesamt eine Tendenz zur erhöhten Gesamtpunktzahl mit höherem T-Stadium 
vor. Es konnten keine signifikanten Unterschiede für die HAD-Skalen zwischen den Gruppen „Tumorlokalisation“ (Kruskal-Wallis-Test, p>0,05), „Transplantatentnahmeregion“, „Transplantatmorphologie“ (jeweils Kruskal-Wallis-Test, p>0,05) oder „Zungenbeweglichkeit“ (Varianzanalyse, $p>0,05$ ) aufgezeigt werden. Im Vergleich der Patienten, die eine Strahlentherapie erhalten haben, mit denen, bei denen dies nicht der Fall war, konnte kein signifikanter Unterschied im HADS-Totalscore oder auch in den HADS-Subskalen gezeigt werden ( $t$-Tests für unabhängige Stichproben für HADS Total und HADS-A, U-Test für HADS-D; jeweils $p>0,05$ ). Auch die Patienten mit einem Tracheostoma unterschieden sich nicht in den HADS-Scores von den Patienten ohne ein Tracheostoma (U-Test für HADS Total und HADS-D, t-Tests für unabhängige Stichproben für HADS-A, jeweils $p>0,05)$.

\subsubsection{Zusammenhang HADS - WR}

Es konnte kein Zusammenhang zwischen dem HADS-Totalscore und der WR aufgezeigt werden (Spearman-Korrelation, $R=-0,182, p=0,087$ ). Es bestand ein schwacher negativer, signifikanter Zusammenhang zwischen der WR und den HADS$D$-Scores (Spearman-Korrelation, $R=-0,247, p=0,019$ ), somit geht ein höherer Grad der Verständlichkeit mit einem tendenziell niedrigeren Depressivitätsscore einher. Für die HADS-A-Scores konnte kein nennenswerter Zusammenhang zur WR (SpearmanKorrelation, $R=-0,069, p=0,518$ ) nachgewiesen werden.

Die Ergebnisübersicht zur statistischen Analyse findet sich in der Tabelle 3. 
Tabelle 3: Sprechverständlichkeit (WR) und ihre Beziehungen zu anderen Parametern

WR und ihre Beziehungen zu anderen Parametern [Testverfahren]

Signifikanzniveau

a) Soziodemographische Parameter

\section{Alter [1]}

Geschlecht [2]

Nikotinabusus [3]

$R=-0,058, p=0,590$

$\mathrm{p}=\mathbf{0 , 0 2 9}$

$p=0,275$

b) Tumorcharakteristika und Therapiemodalitäten

Tumorgröße [4]

T1 vs. T2

T1 vs. T3

T2 vs. T3

T2 vs. T4

T3 vs. T4

T1 vs. T4

Tumorlokalisation [3]

Transplantatentnahmestelle [5]

lokalplastisch* vs. freie Ober-/Unterarmtransplantate**

lokalplastisch* vs. freie Scapula-/Parascapula- bzw. Fibulatransplantate**

freie Ober-/Unterarmtransplantate ${ }^{\star *}$ vs. freie Scapula-/Parascapula- bzw. Fibulatransplantate ${ }^{* \star}$

Transplantatmorphologie [5]

lokalplastisch* vs. faszio-/myo-/kutane Transplantate**

lokalplastisch* vs. faszio-/myo-/kutane Transplantate + freies Knochentransplantat**

lokalplastisch* vs. osteomyokutane Transplantate**

faszio-/myo-/kutane ${ }^{* *}$ vs. faszio-/myo-/kutane Transplantate ${ }^{* *}+$ freies Knochentransplantat

faszio-/myo-/kutane ${ }^{* *}$ vs. osteomyokutane Transplantate ${ }^{* *}$

osteomyokutane $^{* *}$ vs. faszio-/myo-/kutane Transplantate ${ }^{* *}+$ freies Knochentransplantat

Zungenbeweglichkeit [6]

Stufe I vs. Stufe II

Stufe I vs. Stufe III

Stufe II vs. Stufe III

Strahlentherapie [5]

Tracheostoma [2]

c) zweifaktorielle Vergleiche [7]

mit Tumorgröße und Geschlecht

Tumorgröße und WR

Geschlechts und WR

Geschlecht und Tumorgröße

mit Zungenbeweglichkeit und Lokalisation

Zungenbeweglichkeit und WR

Lokalisation und WR

Zungenbeweglichkeit und Lokalisation

$p=0,444$

$p=1,000$

$p=1,000$

$p=1,000$

$p=1,000$

$p=0,009$

$p=0,003$

$p=0,159$

$p<0,001$

$p=0,003$

$p=0,098$

$p=0,022$

$p=0,006$

$\mathrm{p}=\mathbf{0 , 0 4 9}$

$\mathrm{p}=0,099$

$p=0,281$

$p=0,030$

$p=0,001$

$p=0,007$

$p=0,125$

$p=0,040$

mit Zungenbeweglichkeit und Transplantatentnahmeregion

Zungenbeweglichkeit und WR

Transplantatentnahmeregion und WR

Zungenbeweglichkeit und Transplantatentnahmeregion

mit Zungenbeweglichkeit und Transplantatmorphologie

Zungenbeweglichkeit und WR

Transplantatmorphologie und WR

Zungenbeweglichkeit und Transplantatmorphologie

1 Pearson

$2 \mathrm{t}$-Test für unabhängige Stichproben

3 ANOVA

4 Post-Hoc-Paarvergleiche mittels Bonferroni-korrigierter t-Tests

5 U-Test

6 Scheffé-Test

7 Zweifaktorielle ANOVA

*lokale gestielte Gewebeplastik

**freies mikrovaskulär reanastomosiertes Transplantat 


\section{$\underline{6.7 \text { Diskussion }}$}

In der vorliegenden Studie wird der Zusammenhang zwischen dem Grad der Sprachverständlichkeit (gemessen als Worterkennungsrate WR mittels automatischer Spracherkennung) und psychologischen Auffälligkeiten hinsichtlich Ängstlichkeit und Depressivität analysiert.

\subsubsection{WR und Einflussgrößen}

Die WR mit 53,21 $\pm 17,23 \%$ für das vorliegende Patientenkollektiv spiegelt weitgehend die Ergebnisse früherer Studien (49-59\%) wider, die dieselbe Technik zur Messung der Sprechqualität nutzten $[3,7,13,14]$. Die objektive Analyse des Sprechens erlaubt eine genauere statistische Auswertung möglicher Zusammenhänge zu prognoserelevanten soziodemographischen, krankheits- und therapiebezogenen Daten. Gerade die Daten zu soziodemographischen Faktoren und Funktionen wie das Sprechen gründen oft auf methodisch unterschiedlich aufgebauten Untersuchungsreihen und liefern somit keine ohne weiteren Aufwand vergleichbaren Ergebnisse. Deshalb wurde die aus den vorliegenden Quellen abgeleitete Hypothese, dass soziodemographische Faktoren wie höheres Alter, Zugehörigkeit zu männlichem Geschlecht und das Rauchen mit einer geringeren WR einhergehen, ebenso geprüft.

Aus der statistischen Analyse geht hervor, dass weder das Alter noch der Zigarettenkonsum mit niedrigeren Werten zur Sprachverständlichkeit verbunden sind. Aber die Ergebnisse liefern erneut einen Hinweis darauf, dass die Frauen gegenüber den Männern eine höhere WR haben können, wie dies bereits in früheren Untersuchungen gezeigt wurde [3, 9]. Dieser Unterschied scheint nicht auf kleineren Tumorgrößen bei den Frauen zu beruhen und kann somit prognostisch wichtig sein. Zu den Gründen zur besseren Sprachverständlichkeit und ihren umfassenden Bedeutung für das klinische Outcome bedarf es weiterer separater Untersuchungen.

Weiterhin können die Ergebnisse der Studien bestätigt werden, die einen negativen Zusammenhang zwischen Tumorgröße, dem Ausmaß der damit verbundenen therapeutischen Maßnahmen und der Sprechqualität beschreiben [15]. Je größer das Malignom ist, umso umfänglicher werden die Rekonstruktionsmaßnahmen und entsprechend niedriger fällt die WR aus. Mit der vorliegenden Stichprobe lässt sich eine Assoziation von WR mit der Tumorlokalisation, im zweifaktoriellen Ansatz auch die Abhängigkeit der WR mit der Kombination „Tumorlokalisation und Zungenbeweglichkeit“ belegen. Bei der Stichprobe ohne Bewegungseinschränkung sind die WR-Werte bei allen Tumorlokalisationen deutlich höher als bei der Stichprobe mit starker Einschränkung. In der Gruppe mit mittlerer Bewegungseinschränkung haben Patienten nach Tumoren am Mundboden und der Zunge eine deutlich bessere 
WR als nach Tumoren im Unter- oder Oberkiefer. Bei der deskriptiven Betrachtung der Daten bieten sich folgende Erklärungen: eine lokalplastische Defektdeckung fand in den meisten Fällen bei entsprechend kleineren Tumoren statt. Diese geht aufgrund der kleineren Resektionsvolumina entsprechend mit besseren Beweglichkeits- und Sprechergebnissen einher. Im Unter- und Oberkieferbereich nimmt die WR in der vorliegenden Stichprobe mit der Knocheninfiltration stark ab. Im Unterkiefer geht dies mit abnehmender Zungenbeweglichkeit einher, im Oberkiefer war bei betroffenen Patienten aufgrund der fehlenden oronasalen Separation eine suffiziente Lautbildung nicht möglich.

Die Zungenmotilität scheint die WR insgesamt stark zu definieren. Auch sollte beachtet werden, dass bei der Verwendung von freien Transplantaten deren Herkunft und Zusammensetzung von Bedeutung sein können. Die im Umfang der chirurgischen Maßnahmen oft notwendige Tracheostomie geht ebenfalls mit einer schlechteren Sprechqualität einher. Dabei ist die Indikation für die Tracheotomie bestimmt durch das Risiko der Einengung der oberen Atemwege, also damit auch von der Größe, Lokalisation des Tumors und entsprechend dem Ausmaß der chirurgischen Maßnahmen.

\subsubsection{HADS und ihre Einflussgrößen}

Zur Erfassung von Ängstlichkeit und Depressivität gilt in der Psychoonkologie der HADS-Fragebogen als ein etabliertes Verfahren [29, 35-37]. Nach aktueller Studienlage beträgt die mittels der HAD-Skalen erhobene Belastung innerhalb der Allgemeinbevölkerung für Ängstlichkeit 28-33\% und für Depressionen 11-18\% [25, 29]. Bei Patienten mit Tumoroperationen im Kopf- oder Halsbereich liegen die Daten zur Belastung in der Literatur bei Stichproben minimal sechs Monate postoperativ für Ängstlichkeit bei $16-20 \%$ und für Depressionen bei $17-19 \%$; die Belastung für Gesamtscores wird mit 26-68\% angegeben [20, 21, 25, 26, 38, 39]. Dabei muss erwähnt werden, dass die genannten Studien von unterschiedlichen Cut-Off-Werten ausgehen und die Ergebnisse somit nicht ohne weiteres vergleichbar sind.

Für die vorliegende Studie wurden die Cut-Off-Werte für Patienten mit Malignomen im Kopf-Hals-Bereich verwendet. Der Anteil auffälliger HADS-Ergebnisse liegt dabei mit über $43,3 \%$ für alle drei HAD-Skalen (HADS-A, HADS-D und HADS-Totalscores) relativ hoch. Im Gegensatz zu früheren Studien sind also auch nach Abschluss der chirurgischen und adjuvanten Tumortherapie in diesem Kollektiv vermehrt Symptome von Ängstlichkeit erkennbar, nicht nur von Depressivität [4, 21, 25, 26]. In Hinblick auf die soziodemographischen Parameter „weibliches Geschlecht“ und „Rauchen vor Operation“ zeigen sich dabei zwar vereinzelt tendenziell erhöhte Skalenwerte für 
HADS-D, diese erreichen dabei dennoch keine statistische Signifikanz. Somit stehen die genannten soziodemographischen Faktoren im Gegensatz zu früheren Untersuchungen zu Depressivität und Ängstlichkeit nicht im direkten Zusammenhang mit den HADS [21, 22, 30].

Ähnlich der aktuellen Studienlage lässt sich in der vorliegenden Studie die Tendenz zu höheren HADS-Scores mit der Steigerung der Tumorgröße erkennen, und zwar sowohl bei Totalscores als auch innerhalb der Subskalen [21]. Da sich auch ein signifikanter Unterschied zwischen den Tumorgrößen T1 bzw. T4 und der WR belegen lässt, können Fragen zu Wechselwirkungen zwischen WR, HADS und der Tumorgröße von Bedeutung sein. Auch die Lokalisation der Tumore im Oberkiefer geht im deskriptiven Vergleich mit schlechteren WR- und erhöhten HADS-Ergebnissen einher. Hier muss aber die kleine Fallzahl mitberücksichtigt werden, die eine genauere Untersuchung zu Einflüssen von Tumoren im Oberkiefer auf WR und HADS nicht zulässt. Die Ansätze zu Tumorgröße und Lokalisation können in der beschriebenen Studie aber nicht weiterverfolgt werden, da die Signifikanzniveaus bzw. die Fallzahlen für einen multivariaten Vergleich nicht ausreichen.

\subsubsection{WR und HADS-Scores}

In dieser Studie konnte gezeigt werden, dass ein höherer Grad der Sprachverständlichkeit in signifikantem Zusammenhang mit niedrigen Depressivitätsscores einhergeht, es besteht ein schwacher negativer Zusammenhang zwischen diesen Größen. Damit können therapeutische Aspekte zur Rekonstruktion von tumorchirurgisch bedingten Gewebedefekten (definiert durch die Transplantatentnahmeregion und Transplantatmorphologie), Entscheidungen zum Ausmaß der Eingriffsmaßnahmen sowie zum Funktionserhalt der Zungenbeweglichkeit für die psychologische Befindlichkeit der Patienten wichtig sein.

Die Bedeutung des verständlichen Sprechens als Mittel zur Kommunikation ist nicht zu unterschätzen. Die Sprechfähigkeit steht im direkten Zusammenhang mit der Lebensqualität $[1,6]$ und ist von großer Wichtigkeit für die soziale Kompetenz und den emotionalen Gesundheitszustand [18, 20]. Patienten mit der durch die Erkrankung entstandenen Kommunikationseinschränkung werden oft psychischen Belastungen ausgesetzt, die sich in Form von Depressionen äußern können [10, 20]. Dies wird durch die aktuelle Studie bestätigt. Im Allgemeinen scheint es schwierig zu sein, erkrankungs- oder therapierelevante Prädiktoren für ängstliche oder depressive Symptome für Patienten mit Mundhöhlenmalignomen effizient zu erfassen. Aus der beschriebenen Untersuchung geht hervor, dass die erhobenen Daten zu soziodemographischen und therapierelevanten Faktoren nur eine geringe Aussagekraft 
über mögliche Konsequenzen hinsichtlich Ängstlichkeit und Depressivität der Patienten zulassen.

Bei der Interpretation der vorliegenden Ergebnisse muss grundsätzlich berücksichtigt werden, dass eine psychologische Beeinträchtigung multifaktoriell induziert werden kann. Die Erkrankung und die damit einhergehenden Therapie- und Rehabilitationsmaßnahmen können einen Einschnitt im Lebenslauf bedeuten, der auf affektiver Ebene zunächst eine intensive Auseinandersetzung beinhaltet, um eine emotionale Genesung zu ermöglichen. Es wird unter anderem angenommen, dass die emotionale Belastung aus den kommunikativen Einschränkungen resultiert. Aber andererseits könnte auch eine depressive Verstimmung zu Beeinträchtigungen der Sprachverständlichkeit führen. Diese Thematik ist bei Tumorpatienten bis dato nicht ausreichend untersucht oder belegt worden.

\subsubsection{Beziehung zur Lebensqualität}

Es besteht eine enge Beziehung zwischen vielen untersuchten Aspekten und der (gesundheitsbezogenen) Lebensqualität der Patienten. Große Bedeutung für die Lebensqualität haben neben Ängstlichkeit und Depressivität [4, 23] vor allem Radiotherapie [1, 27, 28] und Versorgung mit freiem Transplantat [1, 40]. Auch die Einflüsse von Tumorgröße, Tumorlokalisation und Alter werden vermehrt diskutiert; die Korrelationen erreichen dabei oft keine statistische Signifikanz [6, 28]. Somit bestehen zwischen der somatischen und der affektiven Ebene des Krankheitserlebens zahlreiche Wechselwirkungen, die nicht isoliert voneinander, sondern nur als Gesamtbild betrachtet werden sollten.

\subsubsection{Das psychologischen Befinden und das medizinische Outcome}

Es erscheint von Bedeutung, dem psychologischen Befinden der Patienten vor, während und nach der Therapie gesonderte Aufmerksamkeit zukommen zu lassen. Im Vergleich zu anderen Tumorarten scheinen die Malignome im Kopf-Hals-Bereich mit höherem Auftreten von psychologischen Auffälligkeiten, unter anderem Ängstlichkeit und Depressivität, einherzugehen [24, 36, 41]. Dabei bildet das Vorliegen einer depressiven Verstimmung vor der Therapie den stärksten Prädiktor für Depressionen nach der Behandlungsphase [42]. In diesem Zusammenhang wird dieser Gruppe unter anderem ein hoher Anteil an Suiziden zugeordnet [43]. Die Traumatisierung durch die Erkrankung trifft die Patienten meist emotional unvorbereitet [44]. Für die Auseinandersetzung mit ihren Folgen, unter anderem der Einbuße der Sprachverständlichkeit, wird intensive Informations- und Unterstützungsarbeit seitens des Ärzte- und Pflegepersonals benötigt [44, 45]. Müssen sich die Patienten ohne 
begleitende psychosoziale Betreuung mit den Folgen der Therapie auseinandersetzen, kann es zusätzliche Auswirkungen auf ihre emotionale Verfassung haben. Dies beeinflusst seinerseits negativ die Compliance und das medizinische Outcome der Patienten [38, 39, 41-47].

\subsubsection{Die Bedeutung der Rehabilitation}

Die Rehabilitation hat daher einen gesonderten Stellenwert bei der Behandlung von Patienten mit Tumoren im Kopf-Hals-Bereich. Sie hat unter anderem funktionelle Verbesserungen zum Ziel, die dem Wiedererlangen der oralen Motorik und Artikulation dienen [44, 47, 48]. Dabei kann den Patienten die bedeutende Rolle der Selbstverantwortung für den Erfolg der Rehabilitationsprozesse nahegebracht werden. Hier kann der HADS-Fragebogen eine sinnvolle Ergänzung der Maßnahmen im Rahmen der onkologischen Therapie darstellen, und zwar sowohl im prä- als auch im postoperativen Einsatz. Den Patienten kann geholfen werden, sich idealerweise schon vor dem operativen Eingriff im Rahmen der Depressionsprophylaxe über das Ausmaß der möglichen Veränderungen bewusst zu werden und an der anschließenden Sprechtherapie aktiv teilzunehmen [44]. Des Weiteren steht die postoperative Qualität des Sprechens im direkten Zusammenhang mit der affektiven Ebene des Krankheitserlebens [3]. So beschreiben Studien bei Patienten, die eine Sprechrehabilitation durchlaufen, positive Effekte auf die Adaptationsfähigkeit, die gesundheitsbezogene Lebensqualität und die emotionale Ebene [49].

\section{$\underline{6.8 \text { Fazit }}$}

Neben der rein somatisch orientierten Therapie der Tumorerkrankung im orofazialen Bereich kann die psychoonkologische Betreuung der Patienten notwendig sein. Der Grad der Sprachverständlichkeit 12 bis 16 Monate postoperativ zeigt einen Zusammenhang zum Ausmaß einer depressiven Symptomatik. Die Verbesserung der Sprechfunktion auf allen Ebenen der Behandlung von Patienten mit Malignomen der Mundhöhle kann damit auch positiv auf das emotionale Befinden einwirken. Die Erhebung der Sprechqualität und des Selbsterlebens, hier mittels automatischer Spracherkennung und HADS durchgeführt, können für die Auswahl der adäquaten Rehabilitationsmaßnahmen von großem Nutzen sein.

Diese Studie wurde gefördert durch die Wilhelm-Sander-Stiftung, 2007-2009 [50].

Zuerst veröffentlicht in der Fachzeitschrift Laryngo-Rhino-Otologie 2016 (Georg Thieme Verlag KG Stuttgart / New York): Sprechqualität und psychische 
Beeinträchtigung nach der Therapie von Mundhöhlentumoren / Speech Ability and Psychological Outcome After Treatment of Oral Cancer. N. Böhm, C. Knipfer, A. Maier, T. Bocklet, M. Rohde, F. W. Neukam, F. Stelzle, M. Schuster. Laryngo-Rhino-Otol 2016; 95(09): 610-619; DOI: 10.1055/s-0042-102256

\subsection{Tabellenverzeichnis}

Tabelle 1: Stichprobenbeschreibung

Tabelle 2: Sprechverständlichkeit (WR) - Mittelwerte innerhalb der untersuchten Gruppen

Tabelle 3: Sprechverständlichkeit (WR) und ihre Beziehungen zu anderen Parametern

\subsection{Literaturverzeichnis zur Publikationsschrift}

1. Chandu $A$, Sun KGV, Smith $A C H$. The assessment of quality of life in patients who have undergone surgery for oral cancer: A preliminary report. J Oral Maxillofac Surg 2005; 63: 1606-1612

2. Fingeret MC, Vidrine DJ, Reece GP, Gillenwater AM, Gritz ER. Multidimensional analysis of body image concerns among newly diagnosed patients with oral cavity cancer. Head Neck 2010; 32: 301-309

3. Sambale M, Schuster M, Bocklet T, Maier A, Eysholdt U, Ströbele A, Stelzle F. Speech Intelligibility degree and coping after multimodal therapy of oral squamous carcinoma. Laryngo-Rhino-Otol 2011; 90: 151-156

4. Kollbrunner J, Zbären P, Quack K. Lebensqualitätsbelastung von Patienten mit großen Tumoren der Mundhöhle. Eine deskriptive Studie der psychosozialen Auswirkungen von Krankheit und primär chirurgischer Therapie. Teil 1: Quantität und Qualität des Lebens. HNO 2001; 49: 985-997

5. Schuster M, Stelzle F. Outcome measurements after oral cancer treatment: speech and speech-related aspects - an overview. J Oral Maxillofac Surg 2012; 16: 291-298

6. Borggreven PA, Verdonck-de Leeuw IM, Muller MJ, Heiligers ML, de Bree R, Aaronson NK, Leemans CR. Quality of life and functional status in patients with cancer of the oral cavity and oropharynx: pretreatment values of a prospective study. Eur Arch Otorhinolaryngol 2007; 264: 651-657 
7. Kohler R (2008). Quantitative Bewertung der Verständlichkeit nach der Behandlung kleiner Mundhöhlenkarzinome. 2009; Erlangen, Nürnberg, Univ., unv. Diss.

8. Rhemrev R, Rakhorst HA, Zuidam JM, Mureau MAM, Hovius SER, Hofer SOP. Long-term functional outcome and satisfaction after radial forearm free flap reconstructions of intraoral malignancy resections. J Plast Reconstr Aesthet Surg 2007; 60: $588-592$

9. Suarez-Cunqueiro MM, Schramm A, Schoen R, Seoane-Lestón J, Otero-Cepeda $X L$, Bormann KH, Kokemueller $H$, Metzger M, Diz-Dios P, Gellrich NC. Speech and swallowing impairment after treatment for oral and oropharyngeal cancer. Arch Otolaryngol Head Neck Surg 2008; 134: 1299-1304

10. Cnossen IC, de Bree R, Rinkel RN, Eerenstein SE, Rietveld DH, Doornaert P, Buter J, Langendijk JA, Leemans CR, Verdonck-de Leeuw IM. Computerized monitoring of patient-reported speech and swallowing problems in head and neck cancer patients in clinical practice. Support Care Cancer 2012; 20: 2925-2931

11. Stelzle F, Maier A, Nöth E, Bocklet T, Knipfer C, Schuster M, Neukam FW, Nkenke E. Automatic quantification of speech intelligibility in patients after treatment for oral squamous cell carcinoma. J Oral Maxillofac Surg 2011; 69: 1493-1500

12. Riemann M, Knipfer C, Rohde M, Adler W, Schuster M, Noeth E, Oetter N, Shams N, Neukam FW, Stelzle F. Oral squamous cell carcinoma of the tongue: Prospective and objective speech evaluation of patients undergoing surgical therapy. Head Neck 2015; doi: 10.1002/hed.23994

13. Maier A, Haderlein T, Stelzle F, Nöth E, Nkenke E, Rosanowski F, Schützenberger A, Schuster M. Automatic speech recognition systems for the evaluation of voice and speech disorders in head and neck cancer. EURASIP Journal on Audio, Speech, and Music Processing 2010, 2010: 926951

14. Windrich M, Maier A, Kohler R, Nöth E, Nkenke E, Eysholdt U, Schuster M. Automatic quantification of speech intelligibility of adults with oral squamous cell carcinoma. Folia Phoniatr Logop 2008; 60: 151-156 
15. Stelzle F, Knipfer C, Schuster M, Bocklet T, Nöth E, Adler W, Schempf L, Vieler P, Riemann M, Neukam FW, Nkenke E. Factors influencing relative speech intelligibility in patients with oral squamous cell carcinoma: a prospective study using automatic, computer-based speech analysis. Int J Oral Maxillofac Surg 2013; 42: 1377-1384

16. Mancha de la Plata M, Gías LN, Díez PM, Muñoz-Guerra M, González-García R, Lee GY, Castrejón-Castrejón S, Rodríguez-Campo FJ. Osseointegrated implant rehabilitation of irradiated oral cancer patients. J Oral Maxillofac Surg 2012; 70: 10521063

17. Nelson K, Heberer S, Glatzer. Survival analysis and clinical evaluation of implantretained prostheses in oral cancer resection patients over a mean follow-up period of 10 years. J Prosthet Dent 2007; 98: 405-410

18. Dwivedi RC, St Rose S, Chisholm EJ, Bisase B, Amen F, Nutting CM, Clarke PM, Kerawala CJ, Rhys-Evans PH, Harrington KJ, Kazi R. Evaluation of speech outcomes using English version of the Speech Handicap Index in a cohort of head and neck cancer patients. Oral Oncol 2012; 48: 547-553

19. Liénard A, Merckaert I, Libert Y, Delvaux N, Marchal S, Boniver J, Etienne AM, Klastersky J, Reynaert C, Scalliet P, Slachmuylder JL, Razavi D. Factors that influence cancer patients' anxiety following a medical consultation: impact of a communication skills training programme for physicians. Ann Oncol 2006; 17: 1450-1458

20. Hassanein KAAM, Musgrove BT, Bradbury E. Psychological outcome of patients following treatment of oral cancer and its relation with functional status and coping mechanisms. J Cranio Maxill Surg 2005; 33: 404-409

21. Hammerlid E, Ahlner-Elmqvist M, Bjordal K, Biörklund A, Evensen J, Boysen M, Jannert M, Kaasa S, Sullivan M, Westin T. A prospective multicentre study in Sweden and Norway of mental distress and psychiatric morbidity in head and neck cancer patients. Br J Cancer 1999; 80: 766-774

22. Espie CA, Freedlander E, Campsie LM, Soutar DS, Robertsons AG. Psychological distress at follow-up after major surgery for intra-oral cancer. J Psychosom Res 1989; 33: $441-448$ 
23. Kollbrunner J, Zbären P, Quack K. Lebensqualitätsbelastung von Patienten mit großen Tumoren der Mundhöhle. Teil 2: Krankheitsverarbeitung: Coping, Angst und Depressivität. HNO 2001; 49: 998-1007

24. Massie MJ. Prevalence of depression in patients with cancer. J Natl Cancer Inst Monogr 2004; 32: 57-71

25. Joseph A, Routledgea JA, Burnsa MP, Swindella R, Sykesa AJ, Slevina NJ, Davidsona SE. Value of the Hospital Anxiety and Depression Scale in the follow up of head and neck cancer patients. J Laryngol Otol 2013; 127: 285-294

26. Neilson KA, Pollard AC, Boonzaier AM, Corry J, Castle DJ, Mead KR, Gray MC, Smith DI, Trauer T, Couper JW. Psychological distress (depression and anxiety) in people with head and neck cancers. Med J Aust 2010; 193: 48-51

27. Kelly C, Paleri V, Downs C, Shah R. Deterioration in quality of life and depressive symptoms during radiation therapy for head and neck cancer. Otolaryngol Head Neck Surg 2007; 136: 108-111

28. Rabbels J, Wyzisk M, Siessegger M, Klesper B, Reuther T, Kübler AC. Die Veränderung der Lebensqualität während und nach der Behandlung von Mundhöhlenkarzinomen. Mund Kiefer GesichtsChir 2005; 9: 300-305

29. Olssøn I, Mykletun A, Dahl AA. The Hospital Anxiety and Depressionrating Scale: A cross-selectional study of psychometrics and case finding abilities in general practice. BMC Psychiatry 2005, 5: 46

30. Humphris GM, Rogers SN. The association of cigarette smoking and anxiety, depression and fears of recurrence in patients following treatment of oral and oropharyngeal malignancy. Eur J Cancer Care 2004; 13: 328-335

31. Glas K, Hoppe U, Eysholdt U, Rosanowski F. Smoking, carcinophobia and Voice Handicap Index. Folia Phoniatr Logop 2008; 60: 195-198

32. Maier A, Haderlein T, Eysholdt U, Rosanowski F, Batliner A, Schuster M, Nöth E. PEAKS - a system for the automatic evaluation of voice and speech disorders. Speech Commun 2009, 51: 425-437 
33. Schuster M, Haderlein T, Nöth E, Lohscheller J, Eysholdt U, Rosanowski F. Intelligibility of laryngectomees' substitute speech: automatic speech recognition and subjective rating. Eur Arch Otorhinolaryngol 2006; 263: 188-193

34. Maier A, Hönig F, Bocklet T, Nöth E, Stelzle F, Nkenke E, Schuster M. Automatic detection of articulation disorders in children with cleft lip and palate. J Acoust Soc Am 2009; 126: 2589-2602

35. Zigmond AS, Snaith RP. The Hospital Anxiety and Depression Scale. Acta Psychiatr Scand 1983; 67: 361-370

36. Herrmann C. International experiences with the Hospital Anxiety and Depression Scale - a review of validation data and clinical results. J Psychosom Res 1997; 42: 1741

37. Snaith RP. The Hospital Anxiety And Depression Scale. Health Qual Life Outcomes 2003; $1: 29$

38. Singer S, Kuhnt S, Götze H, et al. Hospital Anxiety and Depression scale cut-off scores for cancer patients in acute care. Br J Cancer 2009; 100: 908-912

39. Singer S, Krauss O, Keszte J, Siegl G, Papsdorf K, Severi E, Hauss J, Briest S, Dietz A, Brähler E, Kortmann RD. Predictors of emotional distress in patients with head and neck cancer. Head Neck 2012; 34: 180-187

40. Bolzoni Villaret A, Cappiello J, Piazza C, Pedruzzi B, Nicolai P. Quality of life in patients treated for cancer of the oral cavity requiring reconstruction: a prospective study. Acta Otorhinolaryngol Ital 2008; 28: 120-125

41. McDonough EM, Boyd JH, Varvares MA, Maves MD. Relationship between psychological status and compliance in a sample of patients treated for cancer of the head and neck. Head Neck 1996; 18: 269-276

42. Karnell LH, Funk GF, Christensen AJ, Rosenthal EL, Magnuson JS. Persistent post-treatment depressive symptoms in patients with head and neck cancer. Head Neck 2006; 28: 453-461 
43. Zeller JL. High suicide risk found for patients with head and neck cancer. J Am Med Assoc 2006; 296: 1716-1717

44. Dingman C, Hegedus PD, Likes C, McDowell P, McCarthy E, Zwilling C. A coordinated, multidisciplinary approach to caring for the patient with head and neck cancer. J Support Oncol 2008; 6: 125-131

45. Llewellyn CD, McGurk M, Weinman J. How satisfied are head and neck cancer (HNC) patients with the information they receive pre-treatment? Results from the satisfaction with cancer information profile (SCIP). Oral Oncol 2006; 42: 726-734

46. Archer J, Hutchison I, Korszun A. Mood and malignancy: head and neck cancer and depression. J Oral Pathol Med 2008; 37: 255-270

47. Samlan RA, Webster KT. Swallowing and speech therapy after definitive treatment for laryngeal cancer. Otolaryngol Clin North Am 2002; 35: 1115 - 1133

48. Okada N, Sasaguri K, Otsuka T, Fujita A, Ito H, Noguchi T, Jinbu Y, Kusama M. Effect of articulatory rehabilitation after oral cancer surgery on higher brain activation. Int J Oral Maxillofac Surg 2014; 43: 933-940

49. de Maddalena $\mathrm{H}$. The influence of early speech rehabilitation with voice prostheses on the psychological state of laryngectomized patients. Eur Arch Otorhinolaryngol 2002; 259: 48-52

50. Stelzle F, Schuster M, Nkenke E, Neukam FW, Nöth E: Automatische, objektive Analyse von Sprechstörungen bei Patienten mit Plattenepithelkarzinomen der Mundhöhle. Arbeitsberichte des Departments Informatik Friedrich-AlexanderUniversität Erlangen-Nürnberg 2008; 40/8: 142-143 


\subsection{Lizenzgenehmigung zur Veröffentlichung der Publikationsschrift}

\section{Thieme}

\section{Via E-Mail}

To:

Frau Natalja Bōhm

Friedrich-Alexander-Universität Erlangen-Nümberg

Pages:

\author{
Barbara Elias \\ Tel.: $+49(0) 7118931681$ \\ Fax: $+49(0) 7118931143$ \\ permissions \&thieme.de
}

\section{Lizenzgenehmigung}

Erlaubnis erteilt von:

Thieme Gruppe

Rüdigerstraße 14, 70469 Stuttgart

Thre Ansprechpartnerin: Barbara Elias

Wir sind mit der Veröffentlichung des folgenden Materials

N. Böhm et al., Sprechqualität und psychische Beeinträchtigung nach der Therapie von Mundhöhlentumoren

Laryngo-Rhino-Otol 2016; 95(09): 610-619

DOI: 10.1055/s-0042-102256 G Georg Thieme Verlag KG 5tuttgart - New York

als Teil threr Promotion, eingereicht an der Friedrich-Alexander-Universität Erlangen-Nürnberg.

kostenlos einverstanden.

Diese Einwilligung gilt für die Nutzung in Print und in elektronischer Form in den Pflichtexemplaren der o.g. wissenschaftlichen Arbeit. Der Artikel darf nur in der akzeptierten und für den Druck verwendeten WORDVersion ohne Thieme-Layout veröffentlicht werden. Nutzung/Bereitstellung der von uns veröffentlichten PDF-Version ist ausdrücklich ausgeschlossen. Weitere Verwertungsrechte und die Erlaubnis zur Bereitstellung auf anderen, kommerziellen Servern werden nicht erteilt.

Soll die Dissertation in den ersten 12 Monaten nach Erscheinen des Artikels bei Thieme über die Hochschule im Internet frei zugänglich gemacht werden, darf der Artikel nicht im Volltext enthalten sein. 12 Monate nach der Erstveröffentlichung der Verlagsversion dūrfen die Autoren die alczeptierte Manuskriptversion auf einem nicht kommerziellen institutionellen Dokumentenserver zugänglich machen.

Genaue Quellenangabe setzen wir voraus.

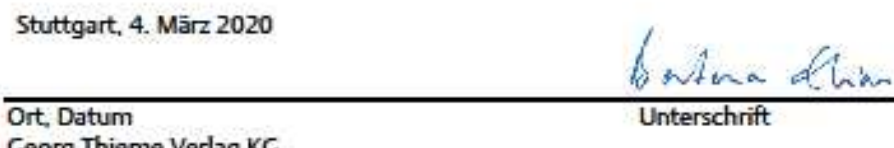

Ceorz Thieme verhig $\mathrm{kl}$ Rudioestast 14 7jalia stutewart

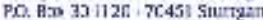
crmary
Tel. $+16(0), 11,3632$, 3

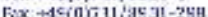
Irverner: www.thkmesom

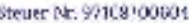
Jat-kd-N. JE $147-3560$. ueģtrrmed altoes

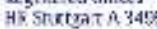

Deubchs Bank Stritpart Accourc No. $1920 y 17$ Bank ID. Ha: 500700 \% BI:- DELTTESS

[34N: DE49 6007 00709 42 001700 


\section{Literaturverzeichnis zur Dissertationsschrift}

1. Steward BW, Kleihues P. World Cancer Report. Lyon: WHO International Agency for Research on Cancer. In 2003; 226-230

2. Bertz J, Giersiepen K, Haberland J, Hentschel S, Kaatsch P, Katalinic A, Stabenow R, Stegmaier C, Ziegler $H$. Krebs in Deutschland. Häufigkeiten und Trends. Gesellschaft der epidemiologischen Krebsregister in Deutschland e.V. (GEKID) in Zusammenarbeit mit dem Robert Koch Institut; 5. überarbeitete, aktualisierte Ausgabe. Saarbrücken 2006. https://www.krebsdaten.de/Krebs/DE/Content/Publikationen/Krebs_ in_Deutschland/vergangene_ausgaben/downloads/krebs_in_deutschland_5.pdf?_blo $\mathrm{b}=$ publicationFile

3. Howaldt HP, Vorast H, Blecher JC et al. Ergebnisse aus dem DÖSAK-Tumorregister. Mund Kiefer GesichtsChir 4. 2000; 216-225

4. Wolff KD, Bootz F, Beck J, Bikowski K, Böhme P, Budach W, Burkhardt A, Danker $H$, Eberhardt W, Engers K, Fietkau R, Frerich B, Gauler T, Germann G, GittlerHebestreit N, Grötz K, Horch R, Ihrler S, Keilholz U, Lell M, Lübbe A, Mantey W, Nusser-Müller-Busch R, Pistner H, Paradies K, Reichert T, Reinert S, Schliephake H, Schmitter M, Singer S, Westhofen M, Wirz S, Wittlinger M. S3-Leitlinie Mundhöhlenkarzinom "Diagnostik und Therapie des Mundhöhlenkarzinoms". Deutsche Gesellschaft für Mund- Kiefer- und Gesichtschirurgie. https://www.awmf.org/uploads/ tx_szleitlinien/007-100OLI_S3_Mundhöhlenkarzinom_122012-122015-abgelaufen.pdf

5. Lippman SM, Spitz M, Trizna Z, Benner SE, Hong WK. Epidemiology, biology, and chemoprevention of aerodigestive cancer. Cancer. 1994; 74(9 Suppl): 2719-25

6. Altieri A, Bosetti C, Talamini R, Gallus S, Franceschi S, Levi F, et al. Cessation of smoking and drinking and the risk of laryngeal cancer. Br J Cancer. 2002; 87(11): 1227-9

7. de Graeff A, de Leeuw JR, Ros WJ, Hordijk GJ, Blijham GH, Winnubst JA. Sociodemographic factors and quality of life as prognostic indicators in head and neck cancer. Eur J Cancer. 2001; 37(3): 332-9 
8. Bagnardi V, Blangiardo M, La Vecchia C, Corrao G. Alcohol consumption and the risk of cancer: a meta-analysis. Alcohol research \& health: the journal of the National Institute on Alcohol Abuse and Alcoholism. 2001; 25(4): 263-70

9. Talamini R, Bosetti C, La Vecchia C, Dal Maso L, Levi F, Bidoli E, et al. Combined effect of tobacco and alcohol on laryngeal cancer risk: a case-control study. Cancer causes \& control: CCC. 2002;13(10): 957-64. Epub 2003/02/18.

10. Figuero Ruiz E, Carretero Peláez MA, Cerero Lapiedra R, Esparza Gómez G, Moreno López LA. Effects of the consumption of alcohol in the oral cavity: relationship with oral cancer. Med Oral 2004

11. Reichart PA. Orale Leukoplakie / Erythroplakie. DGZMK, Hrsg. Wissenschaftliche Stellungnahme. 2007; DZZ 62(01)

12. Herrero R, Castellsague $X$, Pawlita $M$ et al. Human papillomavirus and oral cancer: the International Agency for Research on Cancer multicenter study. J Natl Cancer Inst 2003; 95(23): 1772-83

13. Lindel K, Beer KT, Laissue J, Greiner RH, Aebersold DM. Human papillomavirus positive squamous cell carcinoma of the oropharynx: a radiosensitive subgroup of head and neck carcinoma. Cancer. 2001; 92(4): 805-13

14. Dahlstrom KR, Adler-Storthz K, Etzel CJ, Liu Z, Dillon L, El-Naggar AK, et al. Human papillomavirus type 16 infection and squamous cell carcinoma of the head and neck in never-smokers: a matched pair analysis. Clinical cancer research: an official journal of the American Association for Cancer Research. 2003; 9(7): 2620-6

15. WHO-IARC: IARC Monographs: List of classifications by cancer site 2017. Available from: http://monographs.iarc.fr/ENG/Classification/Table4.pdf; 23 Januar 2018

16. Wittekind C. TNM Klassifikation maligner Tumoren. 8. Auflage ed. Weinheim: Wiley-VCH 2017; ISBN: 978-3-527-34280-8

17. Spence T, Bruce J, Yip KW, et al.: HPV Associated Head and Neck Cancer. Cancers (Basel) 2016; 8(8) 
18. Gillison ML, D'Souza G, Westra W, et al.: Distinct risk factor profiles for human papillomavirus type 16-positive and human papillomavirus type 16-negative head and neck cancers. J Natl Cancer Inst 2008; 100(6): 407-20

19. Gillison ML, Alemany L, Snijders PJ, et al. Human papillomavirus and diseases of the upper airway: head and neck cancer and respiratory papillomatosis. Vaccine 2012; 30(5): F34-54

20. Mallen-St Clair J, Alani M, Wang MB, et al. Human papillomavirus in oropharyngeal cancer: The changing face of a disease. Biochim Biophys Acta 2016; 1866(2): 141-50

21. O'Rorke MA, Ellison MV, Murray LJ, et al. Human papillomavirus related head and neck cancer survival: a systematic review and metaanalysis. Oral Oncol 2012; 48(12): 1191-201

22. Ang KK, Harris J, Wheeler R, et al. Human papillomavirus and survival of patients with oropharyngeal cancer. N Engl J Med 2010; 363(1): 24-35

23. AG HPV der Ständigen Impfkommission (STIKO): Wissenschaftliche Begründung für die Empfehlung der HPV-Impfung für Jungen im Alter von 9 bis 14 Jahren. Epid Bull 2018; 26: 233-250

24. Bloomfield K, Grittner U, Kramer S. Developments in alcohol consumption in reunited Germany. Addiction 2005; 100; 1770-1778

25. Schaller S, Kahnert S, Mons U. Alkoholatlas Deutschland 2017 - Deutsches Krebsforschungszentrum - Verlag Pabst Science Publishers - 1. Auflage 2017

26. Pötschke-Langer M, Kahnert S, Schaller K, Viarisio V, Heidt C, Schunk S, Mons U, Fode K. Tabakatlas Deutschland 2015 Deutsches Krebsforschungszentrum, Pabst Science Publishers. ttps://www.dkfz.de/de/tabakkontrolle/download/Publikationen/sonst Veroeffentlichungen/Tabakatlas-2015-final-web-dp-small.pdf

27. Kahnert S, Schaller K, Mons U. E-Zigaretten: Konsumverhalten in Deutschland 2014-2016. Aus der Wissenschaft - für die Politik, Deutsches 
Krebsforschungszentrum Heidelberg. 2016. www.dkfz.de/de/tabakkontrolle/Aus_der_ Wissenschaft_fuer_die_Politik.html

28. Deutsches Krebsforschungszentrum (Hrsg.): Rauchlose Tabakprodukte: Jede Form von Tabak ist gesundheitsschädlich Heidelberg, 2006. https://www.dkfz.de/de/ tabakkontrolle/download/Publikationen/RoteReihe/Rauchlose_Tabakprodukte_Band6. pdf

29. Listl S, Jansen L. Survival of Patients with Oral Cavity Cancer in Germany. PLoS ONE. 2013; 8(1): e53415

30. Pitiphat W, Diehl SR, Laskaris G, Cartsos V, Douglass CW, Zavras Al. Factors associated with delay in the diagnosis of oral cancer. Journal of dental research. 2002; 81(3): 192-7

31. Jones TM, Hargrove O, Lancaster J, Fenton J, Shenoy A, Roland NJ. Waiting times during the management of head and neck tumours. J Laryngol Otol. 2002; 116(4): 275-9

32. Kollbrunner J, Zbären P, Quack K. Lebensqualitätsbelastung von Patienten mit großen Tumoren der Mundhöhle. Eine deskriptive Studie der psychosozialen Auswirkungen von Krankheit und primär chirurgischer Therapie. Teil 1: Quantität und Qualität des Lebens. HNO 2001; 49: 985-997

33. Kollbrunner J, Zbären $P$, Quack K. Lebensqualitätsbelastung von Patienten mit großen Tumoren der Mundhöhle. Teil 2: Krankheitsverarbeitung: Coping, Angst und Depressivität. HNO 2001; 49: 998-1007

34. Rhemrev R, Rakhorst HA, Zuidam JM, Mureau MAM, Hovius SER, Hofer SOP. Long-term functional outcome and satisfaction after radial forearm free flap reconstructions of intraoral malignancy resections. J Plast Reconstr Aesthet Surg 2007; 60: $588-592$

35. Christoph Leitner C (2007). Mikrochirurgische Rekonstruktionsverfahren in der MKG-Chirurgie: Indikationen, Ergebnisse und Risikofaktoren untersucht anhand einer retrospektiven Analyse des Zeitraumes 1998-2003 unter Verwendung einer neu implementierten Datenbank. Hochschulschrift; 2007, Tübingen, Univ., Diss. 
https://publikationen.uni-tuebingen.de/xmlui/bitstream/handle/10900/44988/pdf/

Dissertation_Mikrochirurgie_online_version_10.02.2007.pdf?sequence=1\&isAllowed=y

36. Chandu A, Sun KGV, Smith ACH. The assessment of quality of life in patients who have undergone surgery for oral cancer: A preliminary report. J Oral Maxillofac Surg 2005; 63: 1606-1612

37. Sambale M, Schuster M, Bocklet T, Maier A, Eysholdt U, Ströbele A, Stelzle F. Speech Intelligibility degree and coping after multimodal therapy of oral squamous carcinoma. Laryngo-Rhino-Otol 2011; 90: 151-156

38. Schuster M, Stelzle F. Outcome measurements after oral cancer treatment: speech and speech-related aspects - an overview. J Oral Maxillofac Surg 2012; 16: 291-298

39. Borggreven PA, Verdonck-de Leeuw IM, Muller MJ, Heiligers ML, de Bree R, Aaronson NK, Leemans CR. Quality of life and functional status in patients with cancer of the oral cavity and oropharynx: pretreatment values of a prospective study. Eur Arch Otorhinolaryngol 2007; 264: 651-657

40. Kohler R (2008). Quantitative Bewertung der Verständlichkeit nach der Behandlung kleiner Mundhöhlenkarzinome. 2009; Erlangen, Nürnberg, Univ., unv. Diss.

41. Suarez-Cunqueiro MM, Schramm A, Schoen R, Seoane-Lestón J, Otero-Cepeda XL, Bormann KH, Kokemueller H, Metzger M, Diz-Dios P, Gellrich NC. Speech and swallowing impairment after treatment for oral and oropharyngeal cancer. Arch Otolaryngol Head Neck Surg 2008; 134: 1299-1304

42. Cnossen IC, de Bree R, Rinkel RN, Eerenstein SE, Rietveld DH, Doornaert P, Buter J, Langendijk JA, Leemans CR, Verdonck-de Leeuw IM. Computerized monitoring of patient-reported speech and swallowing problems in head and neck cancer patients in clinical practice. Support Care Cancer 2012; 20: 2925-2931

43. Stelzle F, Maier A, Nöth E, Bocklet T, Knipfer C, Schuster M, Neukam FW, Nkenke E. Automatic quantification of speech intelligibility in patients after treatment for oral squamous cell carcinoma. J Oral Maxillofac Surg 2011; 69: 1493-1500

44. Riemann M, Knipfer C, Rohde M, Adler W, Schuster M, Noeth E, Oetter N, Shams N, Neukam FW, Stelzle F. Oral squamous cell carcinoma of the tongue: Prospective 
and objective speech evaluation of patients undergoing surgical therapy. Head Neck 2015; doi: 10.1002/hed.23994

45. Maier A, Haderlein T, Stelzle F, Nöth E, Nkenke E, Rosanowski F, Schützenberger A, Schuster M. Automatic speech recognition systems for the evaluation of voice and speech disorders in head and neck cancer. EURASIP Journal on Audio, Speech, and Music Processing 2010, 2010: 926951

46. Windrich $M$, Maier A, Kohler R, Nöth E, Nkenke E, Eysholdt U, Schuster M. Automatic quantification of speech intelligibility of adults with oral squamous cell carcinoma. Folia Phoniatr Logop 2008; 60: 151-156

47. Stelzle F, Knipfer C, Schuster M, Bocklet T, Nöth E, Adler W, Schempf L, Vieler P, Riemann M, Neukam FW, Nkenke E. Factors influencing relative speech intelligibility in patients with oral squamous cell carcinoma: a prospective study using automatic, computer-based speech analysis. Int J Oral Maxillofac Surg 2013; 42: 1377-1384

48. Samlan RA, Webster KT. Swallowing and speech therapy after definitive treatment for laryngeal cancer. Otolaryngol Clin North Am 2002; 35: 1115-1133

49. Okada N, Sasaguri K, Otsuka T, Fujita A, Ito H, Noguchi T, Jinbu Y, Kusama M. Effect of articulatory rehabilitation after oral cancer surgery on higher brain activation. Int J Oral Maxillofac Surg 2014; 43: 933-940

50. de Maddalena $\mathrm{H}$. The influence of early speech rehabilitation with voice prostheses on the psychological state of laryngectomized patients. Eur Arch Otorhinolaryngol 2002; 259: 48-52

51. Fingeret MC, Vidrine DJ, Reece GP, Gillenwater AM, Gritz ER. Multidimensional analysis of body image concerns among newly diagnosed patients with oral cavity cancer. Head Neck 2010; 32: 301-309

52. Hassanein KAAM, Musgrove BT, Bradbury E. Psychological outcome of patients following treatment of oral cancer and its relation with functional status and coping mechanisms. J Cranio Maxill Surg 2005; 33: 404-409 
53. Hammerlid E, Ahlner-Elmqvist M, Bjordal K, Biörklund A, Evensen J, Boysen M, Jannert M, Kaasa S, Sullivan M, Westin T. A prospective multicentre study in Sweden and Norway of mental distress and psychiatric morbidity in head and neck cancer patients. Br J Cancer 1999; 80: 766-774

54. Espie CA, Freedlander E, Campsie LM, Soutar DS, Robertsons AG. Psychological distress at follow-up after major surgery for intra-oral cancer. J Psychosom Res 1989; 33: 441-448

55. Massie MJ. Prevalence of depression in patients with cancer. J Natl Cancer Inst Monogr 2004; 32: 57-71

56. Neilson KA, Pollard AC, Boonzaier AM, Corry J, Castle DJ, Mead KR, Gray MC, Smith DI, Trauer T, Couper JW. Psychological distress (depression and anxiety) in people with head and neck cancers. Med J Aust 2010; 193: 48-51

57. Kelly C, Paleri V, Downs C, Shah R. Deterioration in quality of life and depressive symptoms during radiation therapy for head and neck cancer. Otolaryngol Head Neck Surg 2007; 136: 108-111

58. Rabbels J, Wyzisk M, Siessegger M, Klesper B, Reuther T, Kübler AC. Die Veränderung der Lebensqualität während und nach der Behandlung von Mundhöhlenkarzinomen. Mund Kiefer GesichtsChir 2005; 9: 300-305

59. Singer S, Krauss O, Keszte J, Siegl G, Papsdorf K, Severi E, Hauss J, Briest S, Dietz A, Brähler E, Kortmann RD. Predictors of emotional distress in patients with head and neck cancer. Head Neck 2012; 34: 180-187

60. Bolzoni Villaret A, Cappiello J, Piazza C, Pedruzzi B, Nicolai P. Quality of life in patients treated for cancer of the oral cavity requiring reconstruction: a prospective study. Acta Otorhinolaryngol Ital 2008; 28: 120-125

61. McDonough EM, Boyd JH, Varvares MA, Maves MD. Relationship between psychological status and compliance in a sample of patients treated for cancer of the head and neck. Head Neck 1996; 18: 269-276 
62. Karnell LH, Funk GF, Christensen AJ, Rosenthal EL, Magnuson JS. Persistent post-treatment depressive symptoms in patients with head and neck cancer. Head Neck 2006; 28: 453-461

63. Zeller JL. High suicide risk found for patients with head and neck cancer. J Am Med Assoc 2006; 296: 1716-1717

64. Krischke S1, Weigelt S, Hoppe U, Köllner V, Klotz M, Eysholdt U, Rosanowski F. Quality of life in dysphonic patients. J Voice. 2005 Mar; 19(1): 132-7

65. Dwivedi RC, St Rose S, Chisholm EJ, Bisase B, Amen F, Nutting CM, Clarke PM, Kerawala CJ, Rhys-Evans PH, Harrington KJ, Kazi R. Evaluation of speech outcomes using English version of the Speech Handicap Index in a cohort of head and neck cancer patients. Oral Oncol 2012; 48: 547-553

66. Stelzle F, Oetter N, Goellner LT, Adler W, Rohde M, Maier A, Matthies L, Kesting MR, Knipfer C. Speech intelligibility in patients with oral cancer: An objective baseline evaluation of pretreatment function and impairment. Head Neck. 2019 Apr; 41(4): 1063-1069

67. Schuster M, Maier A, Haderlein T, Nkenke E, Wohlleben U, Rosanowski F, Eysholdt U, Noth E. Evaluation of speech intelligibility for children with cleft lip and palate by means of automatic speech recognition. Int J Pediatr Otorhinolaryngol. 2006; 70(10): 1741-1747

68. Dames F, Maier A, Schützenberger A, Stelzle F, Holst A, Nöth E, Eysholdt U, Schuster M. Intelligibility of Children with Bilateral and Unilateral Cleft Lip and Palate, Laryngo-Rhino-Otol 2009; 88(11): 723-728

69. Knipfer C, Bocklet T, Noeth E, Schuster M, Sokol B, Eitner S, Nkenke E, Stelzle F. Speech intelligibility enhancement through maxillary dental rehabilitation with telescopic prostheses and complete dentures: a prospective study using automatic, computer-based speech analysis. Int J Prosthodont. 2012; 25(1): 24-32

70. Stelzle F, Ugrinovic B, Knipfer C, Bocklet T, Noth E, Schuster M, Eitner S, Seiss M, Nkenke E. Automatic, computer-based speech assessment on edentulous patients with 
and without complete dentures - preliminary results. J Oral Rehabil. 2010; 37(3): 209_ 216

71. Schuster M, Haderlein T, Nöth E, Lohscheller J, Eysholdt U, Rosanowski F. Intelligibility of laryngectomees' substitute speech: automatic speech recognition and subjective rating. Eur Arch Otorhinolaryngol 2006; 263: 188-193

72. Stelzle F, Schuster M, Nkenke E, Neukam FW, Nöth E: Automatische, objektive Analyse von Sprechstörungen bei Patienten mit Plattenepithelkarzinomen der Mundhöhle. Arbeitsberichte des Departments Informatik Friedrich-AlexanderUniversität Erlangen-Nürnberg 2008; 40/8: 142-143

73. Maier A, Haderlein T, Eysholdt U, Rosanowski F, Batliner A, Schuster M, Nöth E. PEAKS - a system for the automatic evaluation of voice and speech disorders. Speech Commun 2009, 51: 425-437

74. Snaith RP. The Hospital Anxiety And Depression Scale. Health Qual Life Outcomes 2003; $1: 29$

75. Herrmann C, Buss U, Snaith R.P. HADS-D Hospital Anxiety and Depression Scale - Deutsche Version. Ein Fragebogen zur Erfassung von Angst und Depressivität in der somatischen Medizin - Testdokumentation und Gebrauchsanweisung. Verlag Hans Huber, Bern 1995

76. Olssøn I, Mykletun A, Dahl AA. The Hospital Anxiety and Depressionrating Scale: A cross-selectional study of psychometrics and case finding abilities in general practice. BMC Psychiatry 2005, 5: 46

77. Herrmann C. International experiences with the Hospital Anxiety and Depression Scale - a review of validation data and clinical results. J Psychosom Res 1997; 42: 1741

78. Singer S, Kuhnt S, Götze H, et al. Hospital Anxiety and Depression scale cut-off scores for cancer patients in acute care. Br J Cancer 2009; 100: 908-912 
79. Balaguer M, Boisguerin A, Galtier A, Gaillard N, Puech M, Woisard V. Factors influencing intelligibility and severity of chronic speech disorders of patients treated for oral or oropharyngeal cancer. Eur Arch Otorhinolaryngol. 2019 Jun; 276(6): 1767-1774

80. Liénard A, Merckaert I, Libert Y, Delvaux N, Marchal S, Boniver J, Etienne AM, Klastersky J, Reynaert C, Scalliet P, Slachmuylder JL, Razavi D. Factors that influence cancer patients' anxiety following a medical consultation: impact of a communication skills training programme for physicians. Ann Oncol 2006; 17: 1450-1458

81. Archer J, Hutchison I, Korszun A. Mood and malignancy: head and neck cancer and depression. J Oral Pathol Med 2008; 37: 255-270

82. Byrne A, Walsh M, Farrelly M, O'Driscoll K. Depression following laryngectomy. A pilot study. Br J Psychiatry. 1993 Aug; 163: 173-6

83. Zarek A, Halczy-Kowalik L, Rzewuska A, Posio V, Stecewicz M. Psychological characteristics versus swallowing and speech rehabilitation efficiency in patients after oral cavity cancer excision. JAMA. 2008 Apr 16; 299(15): 1818-25 


\section{Abkürzungsverzeichnis}

$\begin{array}{ll}\% & \text { Prozent } \\ \text { ANOVA } & \text { Varianzanalyse (Analysis of Variance) } \\ \text { bzW. } & \text { Beziehungsweise } \\ \text { dnt® GmbH } & \text { Drahtlose Nachrichtentechnik GmbH } \\ \text { HADS } & \text { Hospital-Anxiety-and-Depression-Scale (HAD-Scales) } \\ \text { HADS-A } & \text { Hospital-Anxiety-and-Depression-Scale, Subskalen-A } \\ \text { HADS-D } & \text { Hospital-Anxiety-and-Depression-Scale, Subskalen-D } \\ \text { HADS-Total } & \text { Hospital-Anxiety-and-Depression-Scale (Gesamtskalenergebnis) } \\ \text { IBM SPSS Statistics } ® & \text { Statistical Package for the Social Sciences (Softwarefirma IBM) } \\ \text { kHz } & \text { Kilohertz } \\ \text { OP } & \text { Operation } \\ \text { p } & \text { Signifikanzniveau } \\ \text { R } & \text { Korrelationskoeffizient } \\ \text { StAbw } & \text { Standardabweichung } \\ \text { T1 - T4 } & \text { T=Tumor (Tumorgrößen nach TNM-Klassifikation) } \\ \text { vs. } & \text { Versus } \\ \text { WR } & \text { Worterkennungsrate (word recognition rate) } \\ & \end{array}$




\section{Danksagung}

aus datenschutzrechtlichen Gründen entfernt 


\section{Lebenslauf}

aus datenschutzrechtlichen Gründen entfernt 